\title{
Caffeinated Interfaces Enhance Alkaline Hydrogen Electrocatalysis
}

Saad Intikhab ${ }^{1}$, Luis Rebollar ${ }^{1}$, Yawei $\mathrm{Li}^{1}$, Rahul Pai ${ }^{1}$, Vibha Kalra ${ }^{1}$, Maureen Tang ${ }^{1}$, Joshua Snyder ${ }^{1 *}$

${ }^{1}$ Department of Chemical and Biological Engineering, Drexel University, Philadelphia, PA 19104

*Corresponding author:jds43@drexel.edu

\begin{abstract}
The high Pt loading required for hydrogen oxidation (HOR) and evolution (HER) reactions in alkaline fuel cells and electrolyzers adversely impacts the system cost. Here, we demonstrate the use of caffeine as a 'double-layer dopant' to enhance both the HER and HOR of Pt electrodes in base. HER/HOR rates increase by fivefold on $\operatorname{Pt}(111)$ and are accelerated on $\operatorname{Pt}(110), \operatorname{Pt}(\mathrm{pc})$, and $\mathrm{Pt} / \mathrm{C}$ as well. FTIR spectroscopy confirms that caffeine is adsorbed at the Pt surface, forming a self-limiting film through electrochemical deposition. Caffeine films are stable up to $1.0 \mathrm{~V}$ vs. RHE and are readily regenerated through caffeine deposition during load/potential cycling. The findings presented here both identify a potential catalyst additive that can mitigate high Pt loadings in alkaline fuel cells and electrolyzers while opening the door to molecular engineering of solid/liquid interfaces for energy storage and conversion.
\end{abstract}

\section{Introduction}

The hydrogen evolution and oxidation reactions (HER/HOR) remain two of the most fundamental reactions in electrochemistry. Despite decades of research, the source of the $\mathrm{pH}$ dependence of HER/HOR kinetics remains controversial ${ }^{1-8}$. Both reactions are several orders of magnitude slower in alkaline compared to acidic electrolytes, even on Pt. This performance disparity necessitates higher Pt loadings in alkaline fuel cells (AFC) and electrolyzers, adversely impacting system cost. Further commercial advancement of these high $\mathrm{pH}$ devices requires a generational advancement in catalyst technology to drive reduction in precious metal loadings.

Rational electrocatalyst design at alkaline $\mathrm{pH}$ requires a fundamental understanding of the anomalous $\mathrm{pH}$ dependence. Several different schools of thought have evolved over the past decade 
to explain the slower catalytic rates at alkaline $\mathrm{pH}$. An emerging consensus has recognized that hydrogen binding energy (HBE) cannot be the sole activity descriptor in base, and many inconsistencies have been found in the HBE argument ${ }^{9-11}$. Markovic et al. proposed the so-called 'bifunctional theory' which states that in base, both optimal $\mathrm{H}$ and $\mathrm{OH}$ binding are necessary for improved HER/HOR ${ }^{12-15}$. We have showed in our previous works that $\mathrm{OH}_{\mathrm{ad}}$ is not an active participant in the hydrogen reactions and any effect it has on HER/HOR kinetics may be indirect ${ }^{16-}$ 18. Another prominent school of thought hypothesizes that the electrostatic interaction of water dipoles with the electric field influences water reorganization kinetics and can explain the $\mathrm{pH}$ dependence ${ }^{9,19,20}$. While there is good evidence that the electric field is stronger at high $\mathrm{pH}$ than at low $\mathrm{pH}$, a direct link between field strength and water dynamics remains to be proven.

Despite disagreements on the molecular origin of HER/HOR kinetics in base, researchers agree that interfacial water structure is critical ${ }^{6,9,21-23}$. In other words, next-generation electrocatalysts must engineer not only intermediate adsorption energies, but also the electrochemical double-layer structure and dynamics. While the complexity of this task is daunting, literature already provides many examples where manipulating solution structure enhances electrocatalytic rates. In alkaline HER/HOR, cation effects provide a simple demonstration of this approach ${ }^{7,24,25}$. More nuanced effects can be realized with ionic liquid electrolytes in the carbon dioxide reduction reaction $\left(\mathrm{CO}_{2} \mathrm{RR}\right)$ and oxygen reduction reaction $(\mathrm{ORR})^{26-28}$. These and other examples have recognized that the electrolyte, in addition to the electrode, provides opportunities to direct chemical transformations.

In this work, we demonstrate the efficacy of the "double-layer dopant" approach with the molecular additive caffeine. As a hydro- and oxo-phobic molecule, caffeine can inhibit corrosion by preventing oxygen molecules and water from interacting with the electrode surface ${ }^{29}$. While it is hydrophobic, it is slightly polar and is known to affect the hydrogen bonding network and mobility of surrounding water molecules ${ }^{30,31}$. Molecular dynamics simulations, in the absence of an electric field, show that water structures in a complex fashion around the planar caffeine molecules ${ }^{30}$. In this work, we show that electrochemically deposited caffeine 'films' on Pt surfaces yield HER/HOR rate enhancements greater than $5 \mathrm{X}$ in alkaline electrolyte. The impact of caffeine on the reversible hydrogen kinetics exhibits a strong structural sensitivity to the atomic geometry of the underlying Pt surface as well as marked change in effect with electrolyte pH. Preliminary 
insight into the source of the activity enhancement at alkaline $\mathrm{pH}$ suggests that caffeine affects interfacial water in the double layer to facilitate lower transition-state barriers at high $\mathrm{pH}$.

Figure 1(a) shows the HER/HOR polarization curves for $\mathrm{Pt}(111)$ in $0.1 \mathrm{M} \mathrm{KOH}$ with and without caffeine $\left(10^{-4} \mathrm{M}\right)$ in solution. Caffeine significantly reduces the overpotential for HER at $10 \mathrm{~mA} / \mathrm{cm}^{2}$ by $\sim 155 \mathrm{mV}$ and for HOR at $1 \mathrm{~mA} / \mathrm{cm}^{2}$ by $\sim 96 \mathrm{mV}$, while maintaining a similar diffusion-limited current density. Exchange current densities normalized by electrochemically active surface area (ECSA) are listed in Table 1. Throughout this work, geometric current density is reported as $\mathrm{mA} / \mathrm{cm}^{2}$ and ECSA-normalized current density is reported as $\mathrm{mA} / \mathrm{cm}^{2}$ Pt. The negligible impact to the diffusion limited current is counterintuitive, based on Figure 1(b). The adsorbed caffeine appears to block active sites on the Pt surface, as evidenced by the decrease in charge associated with hydrogen underpotential deposition (HuPD). Supplementary Figure S1 shows how varying the concentration of caffeine in solution affects the polarization curves. Increasing the concentration of caffeine in the electrolyte beyond $10^{-4} \mathrm{M}$ does not result in any further change to the HER/HOR polarization curves. Figure $\mathbf{S 2}$ shows a gradual decay in HUPD and $\mathrm{OH}_{a d}$ charge on $\mathrm{Pt}(111)$ as the potential is cycled in a solution containing caffeine. The rate of feature decay is a function of the concentration of caffeine in solution. With continued potential cycling, the $\mathrm{CV}$ features eventually stop decreasing and the corresponding HER/HOR performance stagnates. The absence of any further increase or even decrease in HER/HOR activity points to a self-limiting formation of a caffeine film on the electrode surface. At a steady-state coverage, no further increase in faradaic feature decrease with cycle number, integration of the currents in the electrochemical HuPD and $\mathrm{OH}_{\text {ads/des }}$ regions indicate a decrease in charge by $35 \%$ and $56 \%$ respectively. Figure 1(d) is an ex-situ FTIR spectra of a caffeine film on $\operatorname{Pt}(\mathrm{pc})$ following electrochemical deposition and subsequent rinsing with DI water. After deposition, the caffeine film is stable on the surface and still improves HER/HOR activity after transfer to an electrolyte that does not contain caffeine, see Figures $\mathbf{1}$ and S3. Oxidative cycling in Figure $\mathbf{S 4}$ shows that caffeine films are stable up to potentials of $1.0 \mathrm{~V}$ vs. RHE. Beyond this potential, the caffeine film is slowly removed from the surface through oxidation, eventually yielding the HER/HOR activity of the bare Pt electrode. With caffeine present in the electrolyte, the caffeine film is readily regenerated during potential cycling between 0 and $0.9 \mathrm{~V}$ vs. RHE, Figure S4. The ability to transfer activity to a caffeine-free electrolyte and to regenerate the film once oxidatively removed when caffeine is present in the electrolyte points to the utility of caffeine as a catalyst additive. For 
example, during startup and shutdown, the cathode and anode of water electrolyzers and fuel cells, respectively, can experience potentials greater than $1.0 \mathrm{~V}$ vs. RHE. If caffeine were integrated into such a device, films removed during startup/shutdown events could be readily reformed through exposure to a doped electrolyte. The impact of caffeine on HER/HOR in alkaline electrolyte is also observed on more defected surfaces including $\mathrm{Pt}(110)$ and polycrystalline $\mathrm{Pt}(\mathrm{Pt}(\mathrm{pc}))$, Figure 2(a) and 2(c). For $\mathrm{Pt}(\mathrm{pc})$, the exchange current densities $\left(i_{o}\right)$ improve from $0.30 \mathrm{~mA} / \mathrm{cm}^{2}(0.38$ $\left.\mathrm{mA} / \mathrm{cm}^{2} \mathrm{Pt}\right)$ to $0.86 \mathrm{~mA} / \mathrm{cm}^{2}\left(\left(2.84 \mathrm{~mA} / \mathrm{cm}^{2} \mathrm{Pt}\right)\right)$ whereas for $\mathrm{Pt}(110)$, the exchange current densities (io $)$ improve from $1.03 \mathrm{~mA} / \mathrm{cm}^{2}\left(1.01 \mathrm{~mA} / \mathrm{cm}^{2} \mathrm{Pt}\right)$ to $2.21 \mathrm{~mA} / \mathrm{cm}^{2}\left(6.22 \mathrm{~mA} / \mathrm{cm}^{2} \mathrm{Pt}\right)$. On Pt(110) and $\mathrm{Pt}(\mathrm{pc})$, the HOR current begins to decay at potentials above $\sim 0.6 \mathrm{~V}$ vs. RHE. This decay can be ascribed to the competitive adsorption of $\mathrm{H}_{2}$ and $\mathrm{OH}_{\mathrm{ad}}$ where the surface coverage of spectator $\mathrm{OH}_{\mathrm{ad}}$ at the higher potentials lowers the density of active sites. In the presence of the caffeine film, a significant recovery in the HOR current density is observed at higher potentials, Figure 2(a). We potentially ascribe this recovery to caffeine's association with lower coordinated defect sites or decreasing the $\mathrm{OH}_{\mathrm{ad}}$ binding energy. In the CVs in Figure 2(b), HuPD features are suppressed in the presence of caffeine for both $\mathrm{Pt}(110)$ and $\mathrm{Pt}(\mathrm{pc})$, which have been associated with an $\mathrm{H} / \mathrm{OH}$ exchange on lower coordinated sites ${ }^{10,11,16,32}$. A similar loss in $\mathrm{H} / \mathrm{OH}$ exchange charge is observed from a Pt(111) surface onto which low coordinated Pt-adislands have been deposited ${ }^{12}$, Figure S5. The direct association of caffeine with lower coordinated defects is observed during deposition of the caffeine film where $\mathrm{H} / \mathrm{OH}$ features associated with (110)/(100)-like defects rapidly disappear at early times, Figure S5. Extension of the diffusion limited HOR current density to higher potentials has also been observed for nanoscale catalysts, Pt/C, as shown in Figure S6. The effect of caffeine on $\mathrm{OH}$ adsorption is more directly observed by analyzing its effect on reactions where $\mathrm{OH}_{\mathrm{ad}}$ is a demonstrated reactant ${ }^{33}$, namely $\mathrm{CO}$ oxidation. Figures $2(\mathbf{d})$ and $\mathbf{S 7}$ show that caffeine causes a positive shift in the peak and onset potentials for $\mathrm{CO}$ bulk oxidation and $\mathrm{CO}$ monolayer stripping, respectively. Together, Figures 1, 2 and S7 indicate that the presence of caffeine on the surface reduces the coverage of spectator $\mathrm{OH}_{\mathrm{ad}}$ species, either through a physical competition for adsorption sites or through a weakening of the interaction between the Pt surface and $\mathrm{OH}_{\mathrm{ad}}$. Further work is needed to discern which of these effects is greater.

The impact of caffeine on HER/HOR kinetics is surprising and the source of this activity enhancement remains an open question. In addition to the decay in HuPD and $\mathrm{OH}_{\text {ad }}$ coverage, as determined through integration of the corresponding features in the CVs in Figures 1(b), a 
measurable shift in the $\mathrm{H}$ adsorption threshold towards less positive potentials is observed, indicating either weakening of $\mathrm{HBE}$ or a possible decrease in $\mathrm{H}_{\mathrm{ad}}-\mathrm{H}_{\mathrm{ad}}$ repulsion with a decrease in $\mathrm{H}_{\mathrm{ad}}$ coverage $\mathrm{e}^{34-36}$. Additionally, a positive shift in the onset potential for the formation of $\mathrm{OH}_{\mathrm{ad}}$, Figure 1(b), points to a potential weakening of $\mathrm{OH}_{\mathrm{ad}}$ binding in the presence of the caffeine film. However, several groups have recently highlighted the fact that thermodynamic adsorption energies alone are insufficient to fully describe the HER/HOR kinetics at alkaline $\mathrm{pH}^{9,16,17,19,20}$. If caffeine is weakening the HBE, as indicated by the negative shift in the HuPD onset threshold on $\operatorname{Pt}(111)$ (Figure 1(b)), and the improved HER/HOR kinetics were a direct result of the weakened HBE, a similar result would be expected in acid. As shown in Figure 3, caffeine on Pt(111) results in a decrease in HER/HOR activity at $\mathrm{pH}$ 1, Figure 3(a), while maintaining a similar shift in HUPD threshold potential, Figure 3(b). While oxophilic sites on a Pt surface have been implicated in a beneficial bifunctional mechanism ${ }^{15}$, we have previously argued that $\mathrm{OH}_{\mathrm{ad}}$ is not an active participant in the reaction and must be improving the reaction kinetics indirectly ${ }^{16-18}$. In line with that work, here it is found that adsorbed caffeine on a Pt surface increases HER/HOR activity at alkaline $\mathrm{pH}$, while at the same time weakening $\mathrm{OH}$ binding energy and reducing the oxophilicity of the surface, Figure 1, 2, and S7. While the direct mechanistic impact of interfacial caffeine on the HER/HOR kinetics is not yet fully understood, future work to gain further insight will be guided by current understanding of $\mathrm{pH}$ effects in the reversible hydrogen reaction. It is likely that the thin caffeine film on the surface of Pt disrupts the double layer structure to directly affect the water orientation and dynamics. It has been proposed that at high $\mathrm{pH}$, the stronger electric field at a given potential induces rigidity in the near surface water, lowering reorganization kinetics and impeding charge transfer ${ }^{9,19,20}$. Caffeine at the metal/electrolyte interface may improve alkaline HER/HOR kinetics by weakening the electric field near reversible hydrogen potential, making water reorganization more facile. This interpretation would be supported by the observed behavior at $\mathrm{pH}$ 1, Figure 3. The electric field is already weak in acid near the reversible hydrogen potential and water reorganization kinetics are not expected to play a role in defining the overall reaction rate ${ }^{20,37-39}$. The addition of caffeine to the interface would then just act to block active sites, yielding a decrease in activity. Efforts to understand how caffeine affects the water in the double layer are ongoing.

In summary, we have shown how caffeine as a 'double layer dopant' can enhance the catalytic activity of Pt surfaces in alkaline medium. The most significant improvement is seen for 
the $\operatorname{Pt}(111)$ surface where the HER current densities are $~ 7$ times higher and HOR current densities are $\sim 5$ times higher at $100 \mathrm{mV}$ overpotential. The improvement in HER and HOR is also seen for $\mathrm{Pt}(110), \mathrm{Pt}(\mathrm{pc})$ and commercial $\mathrm{Pt} / \mathrm{C}$ where the exchange current densities are enhanced by 2.2 times, 2.9 times and 1.4 times respectively. FTIR spectroscopy shows that caffeine is specifically adsorbed on the Pt surface and our results suggest that adsorbed caffeine weakens $\mathrm{OH}$ binding energy and possibly affects the water dynamics in the double layer. While the specific source of the activity enhancement may not be definitively identified, our preliminary insights based on the observed results might have implications on understanding the $\mathrm{pH}$ dependence of reversible hydrogen reactions. Molecular double layer dopants present the opportunity to push beyond the activity of standard catalysts, where a nearly infinite library of additive chemistries highlight the potential of this approach for significant impact.

Table 1: ECSA values calculated for bare $\operatorname{Pt}(111)$ and $\operatorname{Pt}(111)+$ caffeine measured by HuPD and $\mathrm{CO}$ stripping and correspondingly normalized HER/HOR exchange current densities.

\begin{tabular}{|l|c|c|c|c|}
\hline & $\begin{array}{c}\text { ECSA (HuPD) } \\
\left(\mathrm{cm}^{2} \mathrm{Pt} / \mathrm{cm}^{2} \text { geo }\right)\end{array}$ & $\begin{array}{c}\text { Exchange Current } \\
\text { Density }\left(i_{o} ;\right. \\
\left.\mathrm{mA} / \mathrm{cm}^{2} \mathrm{Pt}(\mathrm{HUPD})\right)\end{array}$ & $\begin{array}{c}\text { ECSA (CO } \\
\text { stripping) } \\
\left(\mathrm{cm}^{2} \mathrm{Pt} / \mathrm{cm}^{2}{ }_{\text {geo }}\right)\end{array}$ & $\left.\begin{array}{c}\text { Exchange Current } \\
\text { Density }\left(i_{o} ;\right. \\
\mathrm{mA} / \mathrm{cm}^{2} \mathrm{Pt}(\mathrm{CO})\end{array}\right)$ \\
\hline $\mathrm{Pt}(111)-0.1 \mathrm{M} \mathrm{KOH}$ & 0.45 & 0.08 & 0.57 & 0.06 \\
\hline $\begin{array}{l}\mathrm{Pt}(111)+\mathrm{caffeine}- \\
0.1 \mathrm{M} \mathrm{KOH}\end{array}$ & 0.29 & 0.61 & 0.38 & 0.48 \\
\hline $\mathrm{Pt}(111)-0.1 \mathrm{M} \mathrm{HClO}_{4}$ & 0.56 & 3.31 & 0.77 & 2.38 \\
\hline $\begin{array}{l}\mathrm{Pt}(111)+\mathrm{caffeine}- \\
0.1 \mathrm{M} \mathrm{HClO} 4\end{array}$ & 0.26 & 1.86 & 0.12 \\
\hline
\end{tabular}




\section{Acknowledgements}

SI, LR, MHT, and JDS acknowledge support from NSF CBET-Catalysis 1602886.

\section{References}

(1) Bagotsky, V. S.; Osetrova, N. V. Electroanal. Chem. Interfacial Electrochem. 1973, 43, 233-249.

(2) Marković, N. M.; Sarraf, S. T.; Gasteiger, H. A.; Ross, P. N. J. Chem. Soc. Faraday Trans. 1996, 92 (20), 3719-3725.

(3) Sheng, W.; Gasteiger, H. A.; Shao-Horn, Y. J. Electrochem. Soc. 2010, 157 (11), B1529.

(4) Zheng, J.; Zhuang, Z.; Xu, B.; Yan, Y. ACS Catal. 2015, 5 (7), 4449-4455.

(5) Zheng, J.; Nash, J.; Xu, B.; Yan, Y. J. Electrochem. Soc. 2018, 165 (2), H27-H29.

(6) Liu, E.; Li, J.; Jiao, L.; Thi, H.; Doan, T.; Liu, Z.; Zhao, Z.; Huang, Y.; Abraham, K. M.; Mukerjee, S.; Jia, Q. 2019.

(7) Weber, D. J.; Janssen, M.; Oezaslan, M. J. Electrochem. Soc. 2019, 166 (2), F66-F73.

(8) Intikhab, S.; Natu, V.; Li, J.; Li, Y.; Tao, Q.; Rosen, J.; Barsoum, M. W.; Snyder, J. J. Catal. 2019, 371, 325-332.

(9) Ledezma-Yanez, I.; Wallace, W. D. Z.; Sebastián-Pascual, P.; Climent, V.; Feliu, J. M.; Koper, M. T. M. Nat. Energy 2017, 2 (4), 1-7.

(10) Chen, X.; McCrum, I. T.; Schwarz, K. A.; Janik, M. J.; Koper, M. T. M. Angew. Chemie Int. Ed. 2017, 56 (47), 15025-15029.

(11) McCrum, I. T.; Janik, M. J. J. Phys. Chem. C 2016, 120 (1), 457-471.

(12) Subbaraman, R.; Tripkovic, D.; Strmcnik, D.; Chang, K.-C.; Uchimura, M.; Paulikas, A. P.; Stamenkovic, V. R.; Marković, N. M. Science (80-. ). 2011, 334 (December), 12561260.

(13) Strmcnik, D.; Uchimura, M.; Wang, C.; Subbaraman, R.; Danilovic, N.; van der Vliet, D.; Paulikas, A. P.; Stamenkovic, V. R.; Markovic, N. M. Nat. Chem. 2013, 5 (4), 300-306.

(14) Danilovic, N.; Subbaraman, R.; Strmcnik, D.; Chang, K.-C.; Paulikas, A. P.; Stamenkovic, V. R.; Marković, N. M. Angew. Chemie 2012, 51 (50), 12495-12498.

(15) Subbaraman, R.; Tripkovic, D.; Chang, K. C.; Strmcnik, D.; Paulikas, A. P.; Hirunsit, P.; Chan, M.; Greeley, J.; Stamenkovic, V.; Markovic, N. M. Nat. Mater. 2012, 11 (6), 550557.

(16) Intikhab, S.; Snyder, J. D.; Tang, M. H. ACS Catal. 2017, 7 (12), 8314-8319.

(17) Rebollar, L.; Intikhab, S.; Snyder, J. D.; Tang, M. H. J. Electrochem. Soc. 2018, 165 (15), in press. 
(18) Intikhab, S.; Rebollar, L.; Fu, X.; Yue, Q.; Li, Y.; Kang, Y.; Tang, M. H.; Snyder, J. D. Nano Energy 2019, 64 (August), 103963.

(19) Sarabia, F. J.; Sebastián-Pascual, P.; Koper, M. T. M.; Climent, V.; Feliu, J. M. ACS Appl. Mater. Interfaces 2019, 11 (1), 613-623.

(20) Ryu, J.; Surendranath, Y. J. Am. Chem. Soc. 2019, 141 (39), 15524-15531.

(21) Liu, Ershuai; Jiao, Li; Li, Jingkun; Stracensky, Thomas; Richard, Lynne Larochelle; Sun, Qiang; Mukerjee, Sanjeev; Jia, Q. ChemRxiv 2019.

(22) Dubouis, N.; Grimaud, A. Chem. Sci. 2019, 10 (40), 9165-9181.

(23) Zeradjanin, A. R.; Vimalanandan, A.; Polymeros, G.; Topalov, A. A.; Mayrhofer, K. J. J.; Rohwerder, M. Phys. Chem. Chem. Phys. 2017, 19 (26), 17019-17027.

(24) Strmcnik, D.; Kodama, K.; van der Vliet, D.; Greeley, J.; Stamenkovic, V. R.; Marković, N. M. Nat. Chem. 2009, 1 (6), 466-472.

(25) Chung, H. T.; Choe, Y. K.; Martinez, U.; Dumont, J. H.; Mohanty, A.; Bae, C.; Matanovic, I.; Kim, Y. S. J. Electrochem. Soc. 2016, 163 (14), F1503-F1509.

(26) Kumeda, T.; Tajiri, H.; Sakata, O.; Hoshi, N.; Nakamura, M. Nat. Commun. 2018, 9 (1).

(27) Snyder, J.; Fujita, T.; Chen, M. W.; Erlebacher, J. Nat. Mater. 2010, 9 (11), 904-907.

(28) Faggion, D.; Gonçalves, W. D. G.; Dupont, J. Front. Chem. 2019, 7 (MAR), 1-8.

(29) De Souza, F. S.; Giacomelli, C.; Gonçalves, R. S.; Spinelli, A. Mater. Sci. Eng. C 2012, 32 (8), 2436-2444.

(30) Tavagnacco, L.; Schnupf, U.; Mason, P. E.; Saboungi, M. L.; Cesàro, A.; Brady, J. W. J. Phys. Chem. B 2011, 115 (37), 10957-10966.

(31) Smit, W. J.; van Dam, E. P.; Cota, R.; Bakker, H. J. J. Phys. Commun. 2019, 3 (2), 025010 .

(32) Van Der Niet, M. J. T. C.; Garcia-Araez, N.; Hernández, J.; Feliu, J. M.; Koper, M. T. M. Catal. Today 2013, 202 (1), 105-113.

(33) Li, Y.; Hart, J.; Profitt, L.; Intikhab, S.; Chatterjee, S.; Taheri, M.; Snyder, J. ACS Catal. 2019, 9 (10), 9311-9316.

(34) Marković, N. M.; Grgur, B. N.; Ross, P. N. J. Phys. Chem. B 1997, 5647 (97), 5405-5413.

(35) Ross, P. N. Surface Science. 1981, pp 463-485.

(36) Markovic, N. M.; Ross Jr., P. N. Surf. Sci. Rep. 2002, 45 (4-6), 117-229.

(37) Rizo, R.; Sitta, E.; Herrero, E.; Climent, V.; Feliu, J. M. Electrochim. Acta 2015, 162, $138-145$.

(38) Martínez-Hincapié, R.; Sebastián-Pascual, P.; Climent, V.; Feliu, J. M. Russ. J. Electrochem. 2017, 53 (3), 227-236. 
(39) Rebollar, L.; Intikhab, S.; Snyder, J. D.; Tang, M. H. J. Phys. Chem. Lett. 2020, 23082313. 


\section{Figures}
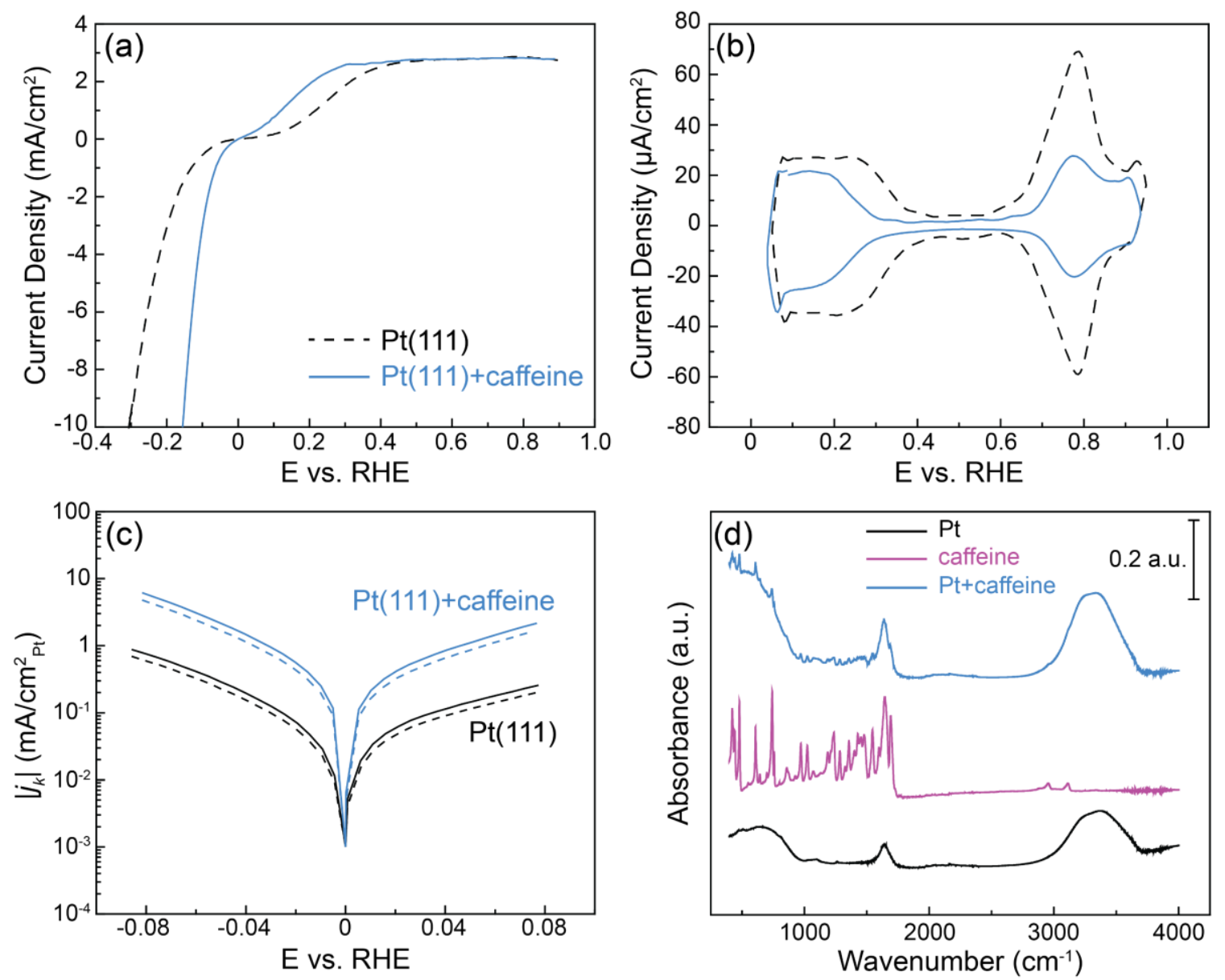

Figure 1: (a) HER/HOR polarization curves for $\mathrm{Pt}(111)$ (black dashed line) and $\mathrm{Pt}(111)+$ caffeine (blue solid line) in $\mathrm{H}_{2}$ saturated $0.1 \mathrm{M} \mathrm{KOH}$ (anodic sweep, $50 \mathrm{mV} / \mathrm{s}$ ). (b) $\mathrm{CV}$ of $\mathrm{Pt}(111)$ (black dashed line) and $\mathrm{Pt}(111)+$ caffeine (blue solid line) in Ar purged $0.1 \mathrm{M}$ $\mathrm{KOH}$. (c) Tafel plots for $\mathrm{Pt}(111)$ (black) and $\mathrm{Pt}(111)+$ caffeine (blue) (solid lines are normalized by HuPD ECSA and dashed lines are normalized by CO stripping ECSA). (d) FTIR spectra of bare Pt (black), caffeine molecule (purple), and caffeine film on Pt (blue). 

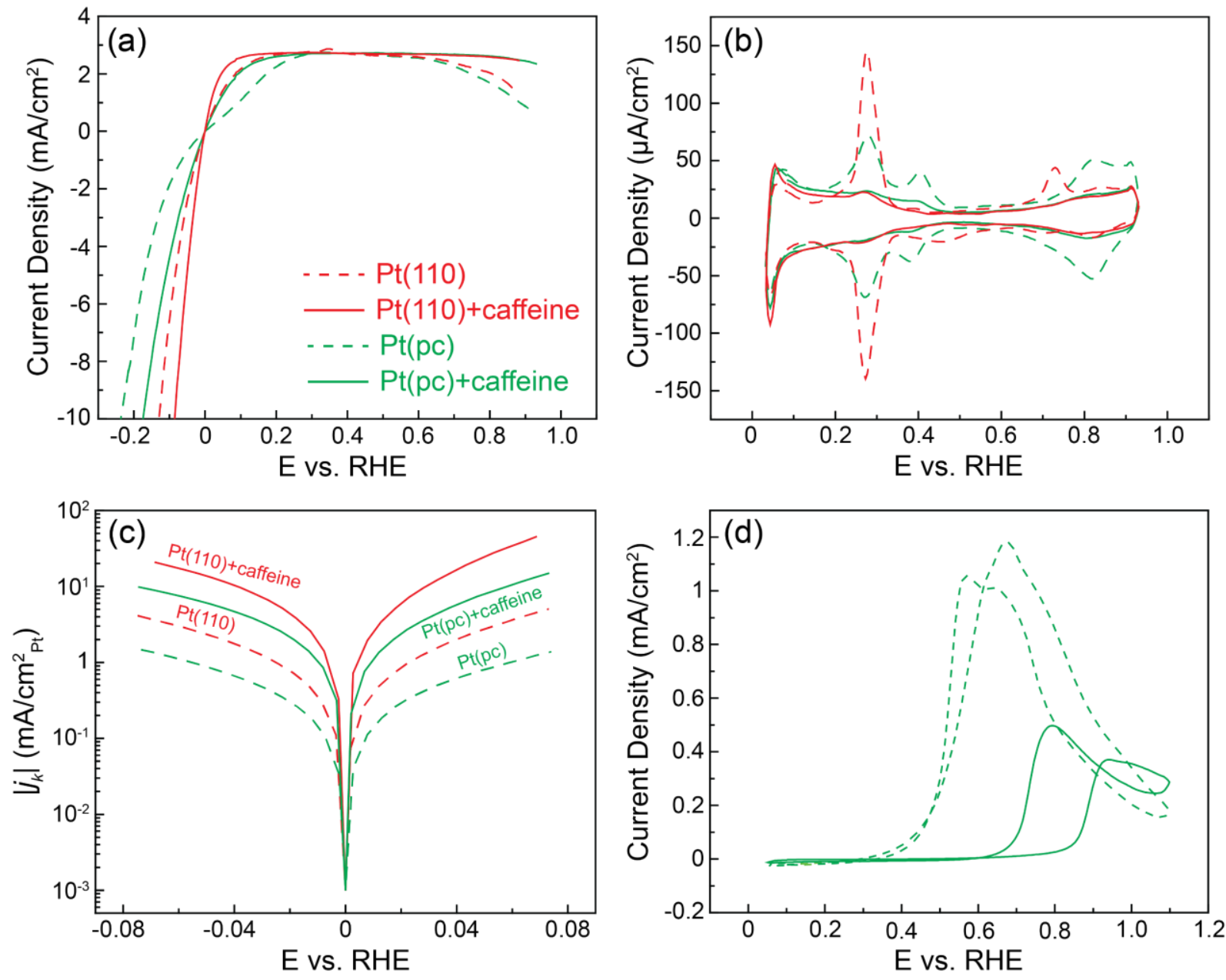

Figure 2: (a) HER/HOR polarization curves for $\mathrm{Pt}(110)$ (red dashed line), $\mathrm{Pt}(110)+$ caffeine (red solid line), $\mathrm{Pt}(\mathrm{pc})$ (green dashed line), and $\mathrm{Pt}(\mathrm{pc})+$ caffeine (green solid line) in $\mathrm{H}_{2}$ saturated $0.1 \mathrm{M}$ $\mathrm{KOH}$ (anodic sweep, $50 \mathrm{mV} / \mathrm{s}$ ). (b) $\mathrm{CV}$ of $\mathrm{Pt}(110)$ (red dashed line), $\mathrm{Pt}(110)+$ caffeine (red solid line), $\mathrm{Pt}(\mathrm{pc})$ (green dashed line), and $\mathrm{Pt}(\mathrm{pc})+$ caffeine (green solid line) in Ar purged $0.1 \mathrm{M} \mathrm{KOH}$. (c) Tafel plots generated from the corresponding polarization curves in (a). (d) $\mathrm{CO}$ electrooxidation on $\mathrm{Pt}(\mathrm{pc})$ (green dashed line) and $\mathrm{Pt}(\mathrm{pc})+$ caffeine (green solid line) $\mathrm{CO}$ saturated $0.1 \mathrm{M} \mathrm{HClO}_{4}$, $1600 \mathrm{rpm}$. 

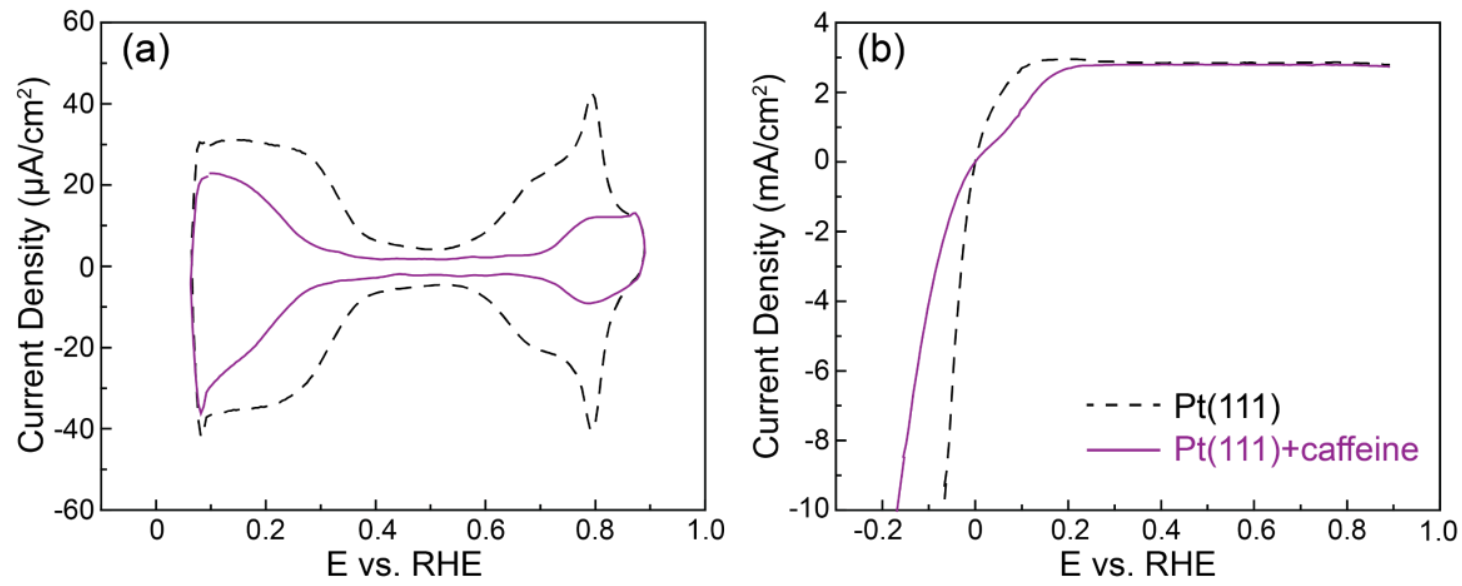

Figure 3: (a) CV of $\mathrm{Pt}(111)$ (black dashed line) and $\mathrm{Pt}(111)+$ caffeine (purple solid line) in Ar purged $0.1 \mathrm{M} \mathrm{HClO}_{4}$. (b) HER/HOR polarization curves for $\mathrm{Pt}(111)$ (black dashed line) and $\mathrm{Pt}(111)+$ caffeine (purple solid line) in $\mathrm{H}_{2}$ saturated $0.1 \mathrm{M} \mathrm{HClO}_{4}$. 


\section{TOC Graphic}

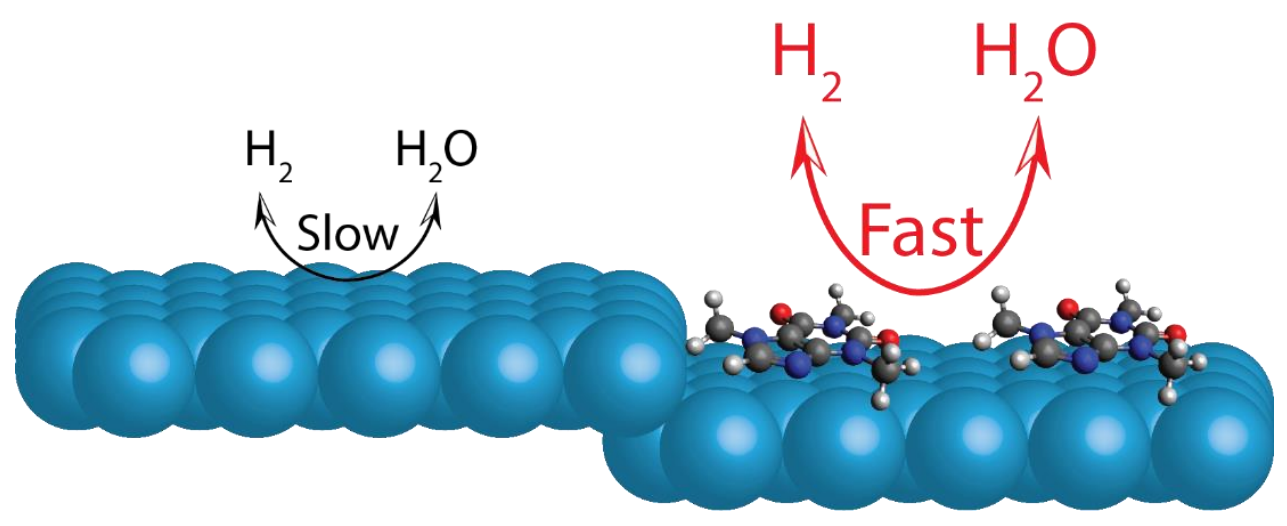




\section{Supporting Information}

\section{Caffeinated Interfaces Enhance Alkaline Hydrogen Electrocatalysis}

Saad Intikhab ${ }^{1}$, Luis Rebollar ${ }^{1}$, Yawei Li $^{1}$, Rahul Pai ${ }^{1}$, Vibha Kalra ${ }^{1}$, Maureen Tang ${ }^{1}$, Joshua Snyder $^{1 *}$

${ }^{1}$ Department of Chemical and Biological Engineering, Drexel University, Philadelphia, PA 19104

*Corresponding author: jds43@drexel.edu 


\section{Methods}

\subsection{Electrochemical Measurements}

Electrochemical measurements were made at room temperature in a FEP electrochemical cell using an Autolab PGSTAT302N potentiostat with a rotating disc electrode (RDE) setup (Pine Instruments). Pt mesh (99.9\%, Alfa Aesar) bonded to the end of a Pt wire (99.9\%, Alfa Aesar) was used as a counter electrode. The $\mathrm{Ag} / \mathrm{AgCl}$ (BASi) reference electrode was calibrated against a hydrogen reference and separated from the working electrode by an electrolyte bridge. All potentials reported in this manuscript are referenced to the reversible hydrogen electrode (RHE) and corrected for iR loss. Prior to any electrochemical experiments, the electrochemical cell and electrodes were cleaned by soaking in a solution of concentrated 1:1 $\mathrm{H}_{2} \mathrm{SO}_{4}: \mathrm{HNO}_{3}$ for at least 2 hours followed by rinsing and boiling in Millipore (Milli-Q Synthesis A10) water. Electrolytes were made from high purity precursors: $\mathrm{KOH}$ (Sigma Aldrich, semiconductor grade, 99.99\% [metal basis]), $\mathrm{HClO}_{4}(70 \mathrm{wt} \%$, Suprapur, Merck) and Millipore water (18.2 M $\Omega$-cm, < $3 \mathrm{ppb}$ TOC).

Cyclic voltammetry (CV) profiles were obtained in Ar-(research grade, Airgas) purged electrolyte with a potential range of $0.05-0.9 \mathrm{~V}$ vs. RHE at a scan rate of $50 \mathrm{mV} / \mathrm{s}$. HER/HOR polarization curves were obtained through potential cycling between $-0.3-0.9 \mathrm{~V}$ vs. $\mathrm{RHE}$ in $\mathrm{H}_{2}$ saturated electrolyte at a rotation rate of $1600 \mathrm{rpm}$. All polarization curves in this paper are normalized by the geometric surface area. Experiments were repeated more than thrice in order to confirm that the results were repeatable (Figure S10-12). For the highly sensitive Pt (111) single crystal surface, two different individuals performed the experiments separately in order to confirm the consistency of results. Tafel plots are normalized by the electrochemical active surface area (ECSA) as determined by the area under the $\mathrm{H}_{\text {upd }}$ region/CO stripping curve for $\mathrm{Pt}$ (111) and H/OH exchange region for the other Pt surfaces. Kinetic current densities for HOR, used for Tafel plots and calculation of exchange current densities $\left(i_{o}\right)$, were calculated using the Koutecky-Levich equation to adjust for mass transport limitations:

$$
\frac{1}{i_{n}}=\frac{1}{i_{k}}+\frac{1}{i_{d}}
$$

where, $i_{n}$ is the measured current density, $i_{d}$ is the diffusion-limited current density, and $i_{k}$ is the kinetic current density. 
The exchange current densities $\left(i_{o}\right)$ are extracted from the micropolarization region $(\eta= \pm 10$ $\mathrm{mV}$ ). Butler-Volmer equation (for small overpotentials (n)) can be linearized into the form:

$$
i_{o}\left(\alpha_{a}+\alpha_{b}\right)=\frac{R T}{F} \frac{i_{n}}{\eta}
$$

where, $\alpha_{\mathrm{a}}$ and $\alpha_{\mathrm{b}}$ are anodic and cathodic transfer coefficients, $\mathrm{F}$ is Faraday's constant, $\mathrm{R}$ is the ideal gas constant, and $\mathrm{T}$ is temperature.

Using the linearized form of Butler-Volmer, exchange current density is calculated by multiplying the slope of the lines of the micropolarization regions, shown in Figure S13-14, by $\mathrm{RT} / \mathrm{F}$. The value of $\left(\alpha_{a}+\alpha_{b}\right)$ is assumed to be 1 .

\subsection{Electrode preparation and caffeine deposition}

$\operatorname{Pt}(111)$ (Princeton Scientific, $5 \mathrm{~mm}$ dia.), Pt(110) (Princeton Scientific, $5 \mathrm{~mm}$ dia.), and $\mathrm{Pt}(\mathrm{pc})$ were annealed at $1100{ }^{\circ} \mathrm{C}$ for 10 minutes under $3 \% \mathrm{H}_{2} / \mathrm{Ar}$ flow (Airgas). After cooling for 5 minutes in the same gas, the disk was protected with a drop of Millipore water, mounted in the RDE holder and transferred to the electrolyte with immersion under potential control at $0.1 \mathrm{~V}$. For caffeine deposition, caffeinated electrolytes were used which were prepared by adding caffeine (>99\%, Sigma Aldrich) to $60 \mathrm{~mL}$ of $0.1 \mathrm{M} \mathrm{KOH} / 0.1 \mathrm{M} \mathrm{HClO}_{4}$ to obtain concentrations of $10^{-5}$ $\mathrm{M} / 10^{-4} \mathrm{M}$ caffeine in solution. Following immersion of the prepared electrode into the Ar purged electrolyte, the potential was cycled between $0.05-0.9 \mathrm{~V}$ at $50 \mathrm{mV} / \mathrm{s}$. The potential cycling led to the deposition of caffeine on the electrode surface as shown by the gradual suppression of CV features with each subsequent cycle (Figure S9). All CVs reported in the manuscript show the steady-state current response after deposition cycling.

\section{CO stripping/bulk CO oxidation}

The CO stripping/bulk CO oxidation measurements were completed in a FEP cell using an Autolab PGSTAT302N potentiostat in a RDE setup. The $\mathrm{Ag} / \mathrm{AgCl}$ (BASi) reference electrode was used with a glass double-junction jacket to limit contamination of the working electrodes and Pt mesh was used as the counter electrode. In the $\mathrm{CO}$ stripping procedure, the working electrode potential was held constant at $0.2 \mathrm{~V}$ as $\mathrm{CO}$ was bubbled into the electrolyte. When the current decayed to zero due to $\mathrm{CO}$ passivation, $\mathrm{CO}$ bubbling was stopped, and the electrolyte was purged 
with Ar for 20 minutes after which CO was stripped from the surface by cycling the potential to $1.1 \mathrm{~V}$ vs RHE. For bulk CO oxidation, the working electrode was transferred to $\mathrm{CO}$ purged electrolyte and the potential was cycled from $0.1-1.1 \mathrm{~V}$. For caffeinated experiments, caffeine was deposited on the working electrodes prior to $\mathrm{CO}$ stripping or bulk $\mathrm{CO}$ oxidation measurements in uncaffeinated electrolyte. 
a)

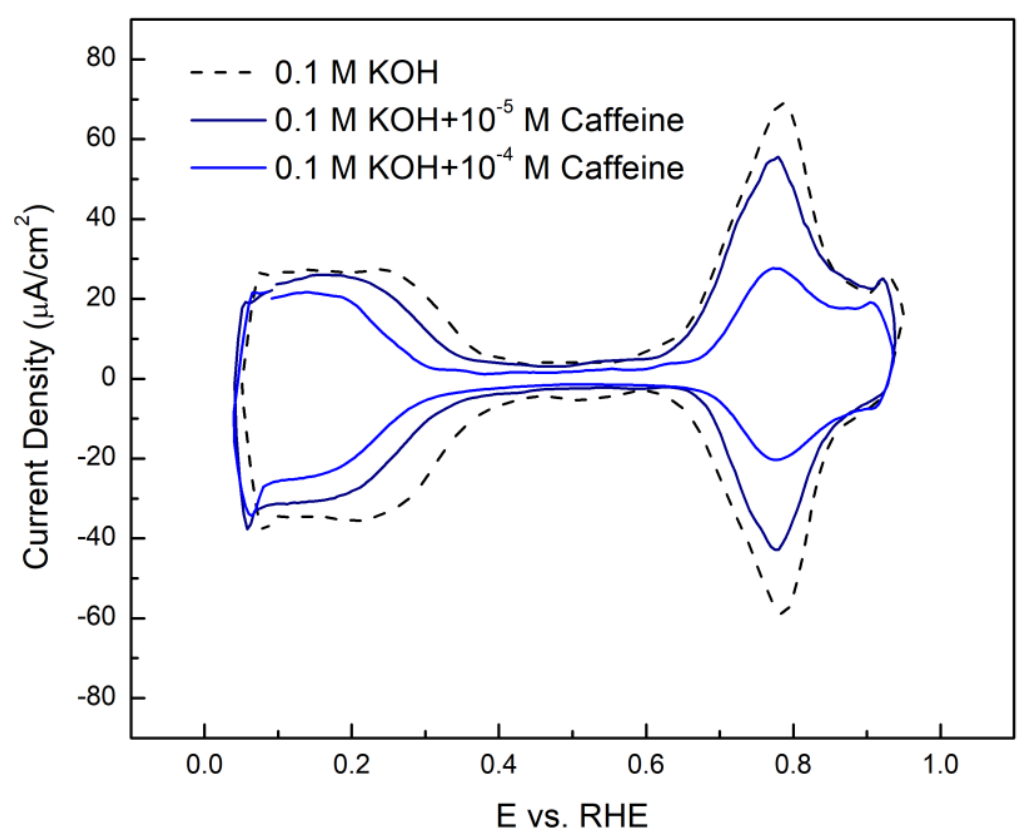

b)

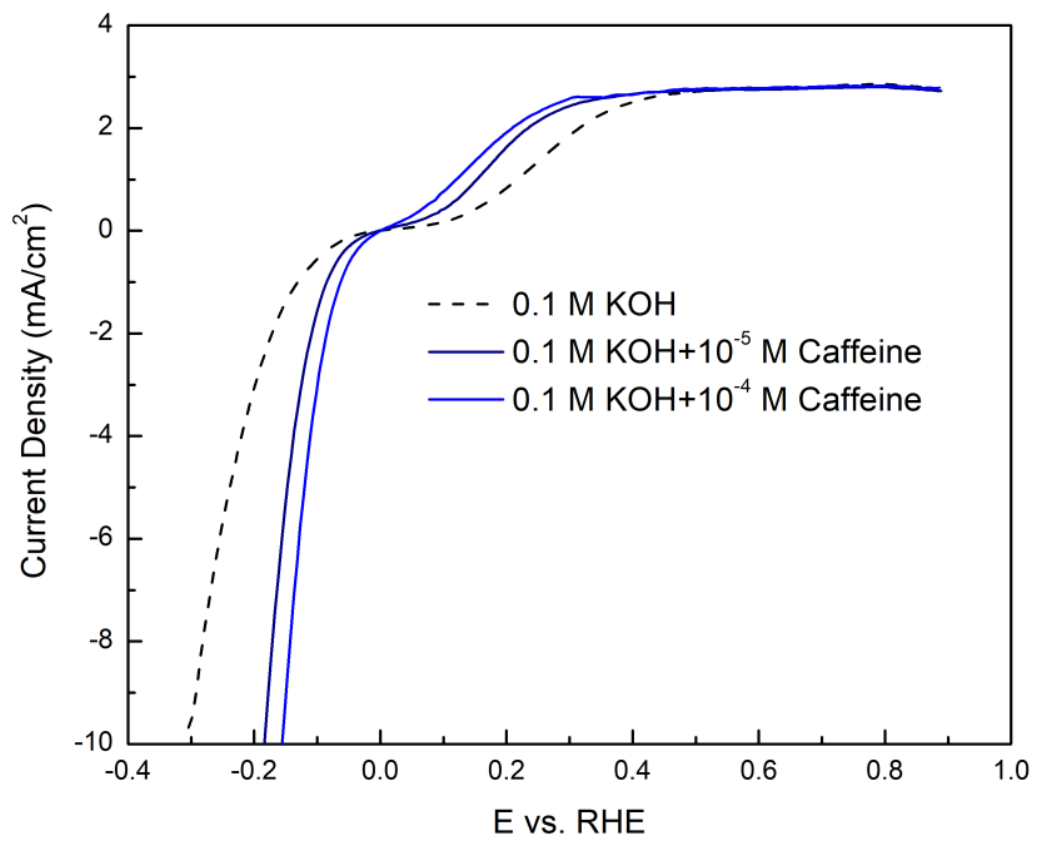

Figure S1: a) CVs and b) HER/HOR polarization curves of $\mathrm{Pt}$ (111) in $0.1 \mathrm{M} \mathrm{KOH}$ with: no caffeine, $10^{-5} \mathrm{M}$ caffeine and $10^{-4} \mathrm{M}$ caffeine at a scan rate of $50 \mathrm{mV} / \mathrm{s}$. 


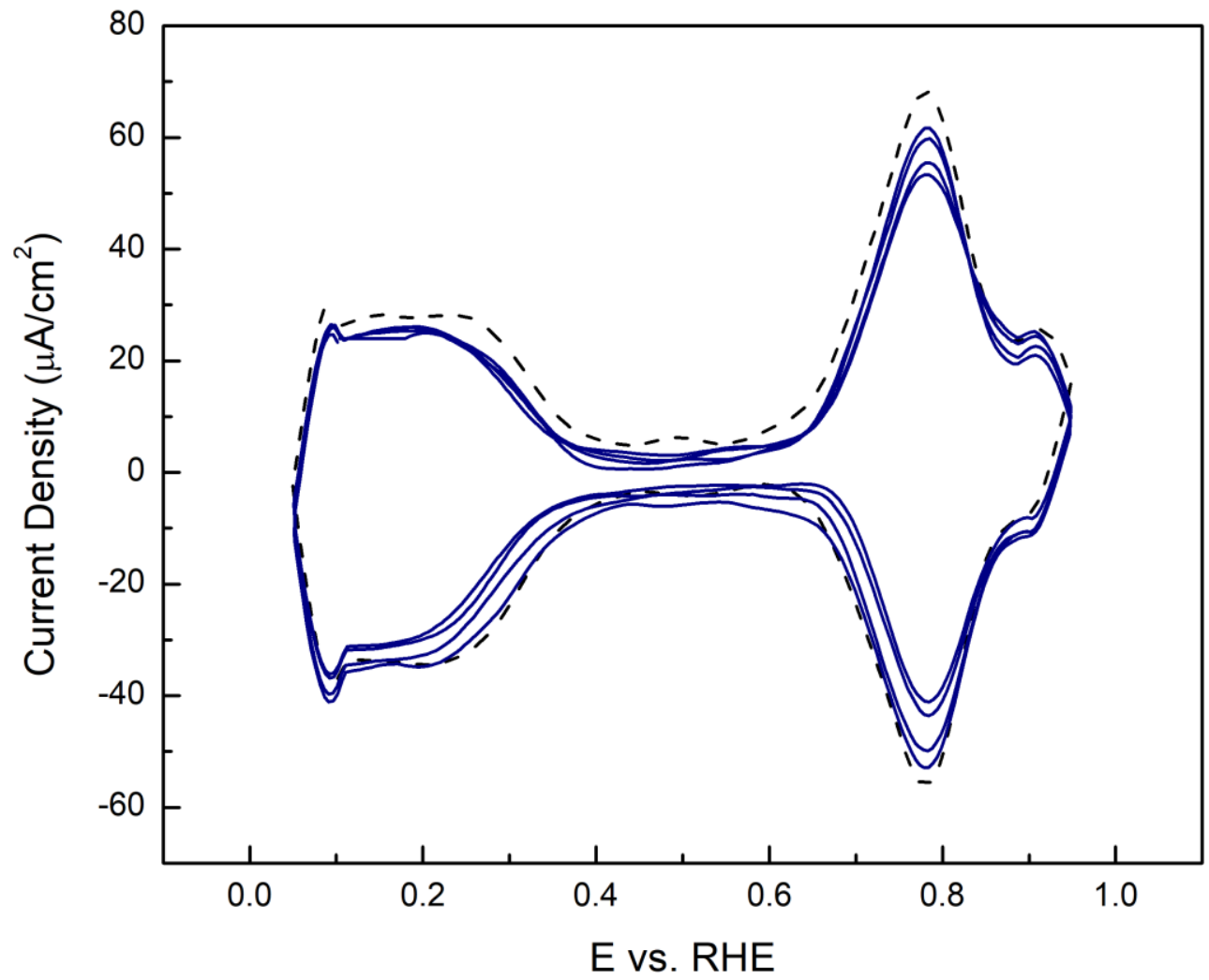

Figure S2: Gradual decay in $\mathrm{HuPD}_{\mathrm{u}}$ and $\mathrm{OH}_{\mathrm{ad}}$ on $\mathrm{Pt}(111)$ with potential cycling in $0.1 \mathrm{M} \mathrm{KOH}$ $+10^{-5} \mathrm{M}$ caffeine at a scan rate of $50 \mathrm{mV} / \mathrm{s}$. 


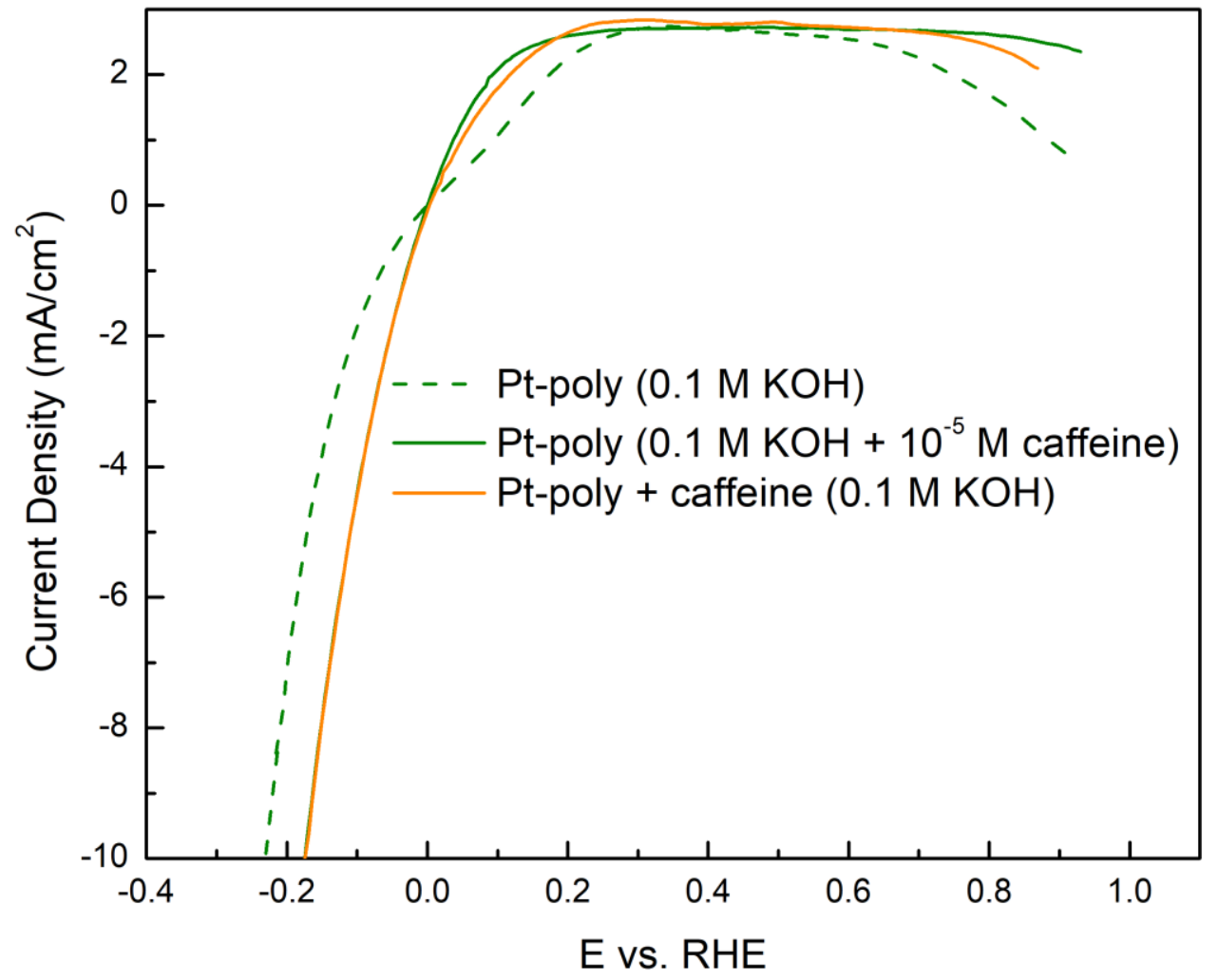

Figure S3: HER/HOR polarization curves at a scan rate of $50 \mathrm{mV} / \mathrm{s}$ of $\mathrm{Pt}$-poly in $\mathrm{H}_{2}$ purged 0.1 M KOH with: no caffeine (dashed green); $10^{-5} \mathrm{M}$ caffeine (solid green) and Pt-poly + caffeine with no caffeine in solution (solid orange). 


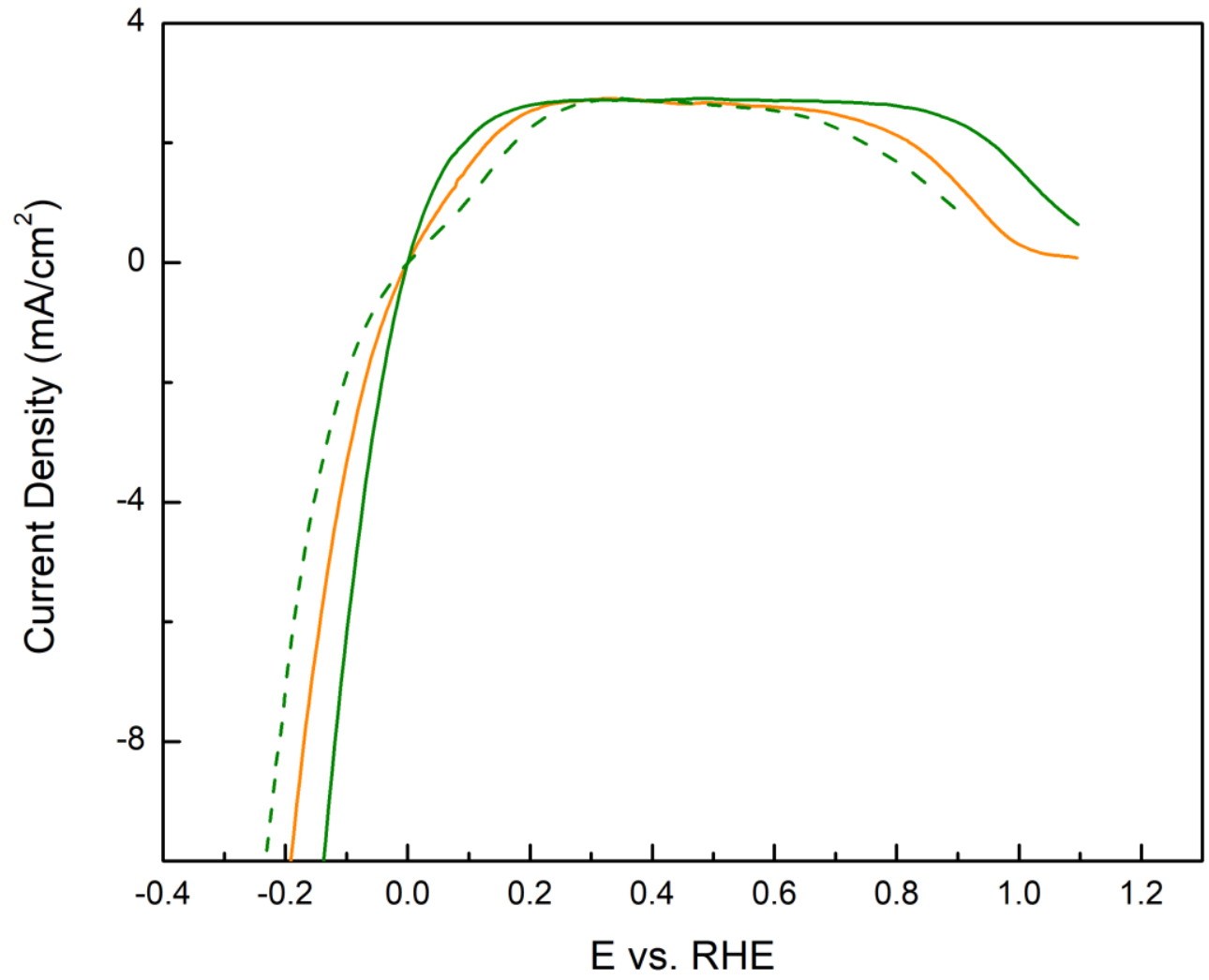

Figure S4: HER/HOR polarization curves at a scan rate of $50 \mathrm{mV} / \mathrm{s}$ of $\mathrm{Pt}$-poly in $\mathrm{H}_{2}$ purged 0.1 M KOH with: no caffeine (dashed green); $10^{-5} \mathrm{M}$ caffeine (solid green) and Pt-poly + caffeine with no caffeine in solution (solid orange). 


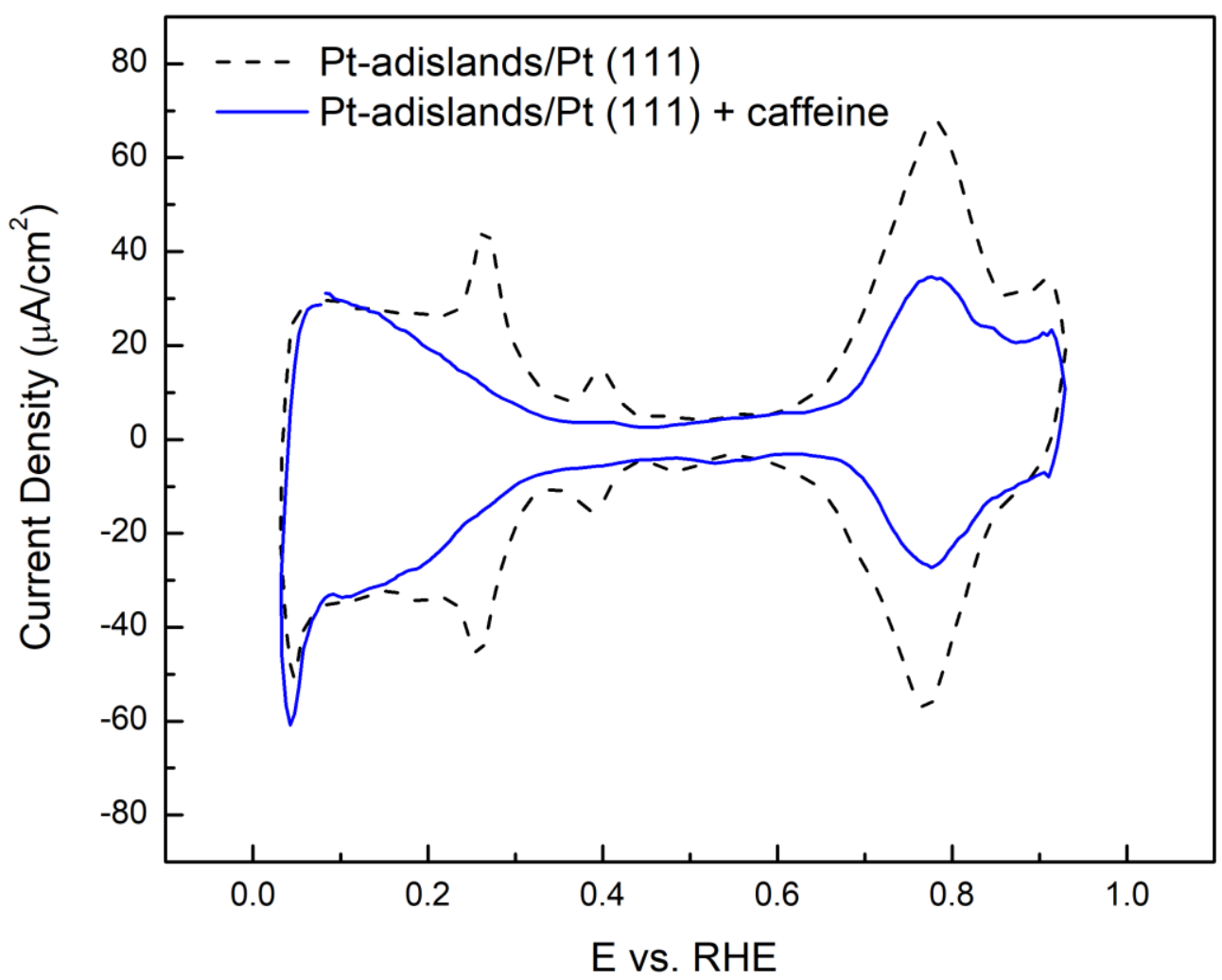

Figure S5: $\mathrm{CV}$ of $\mathrm{Pt}(111)+\mathrm{Pt}$ adislands in Ar purged $0.1 \mathrm{M} \mathrm{KOH}$ at $50 \mathrm{mV} / \mathrm{s}$ with no caffeine and $10^{-5} \mathrm{M}$ caffeine. 
a)

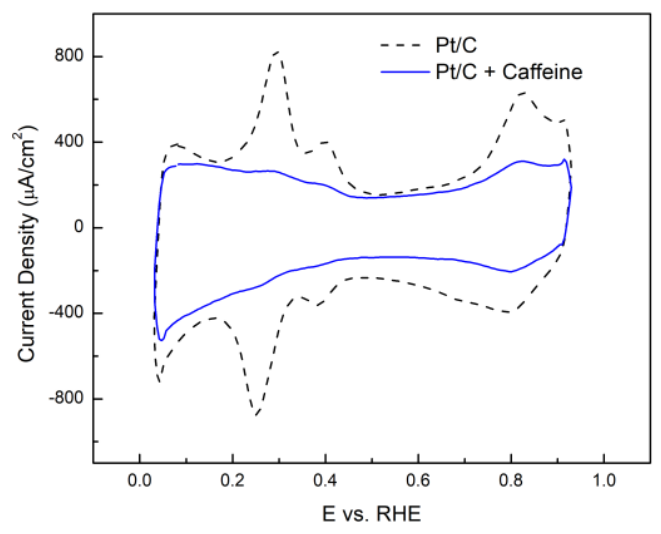

b)

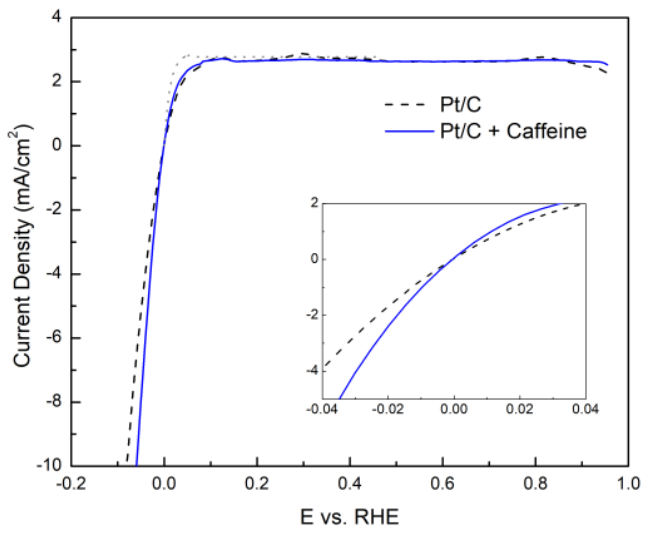

c)

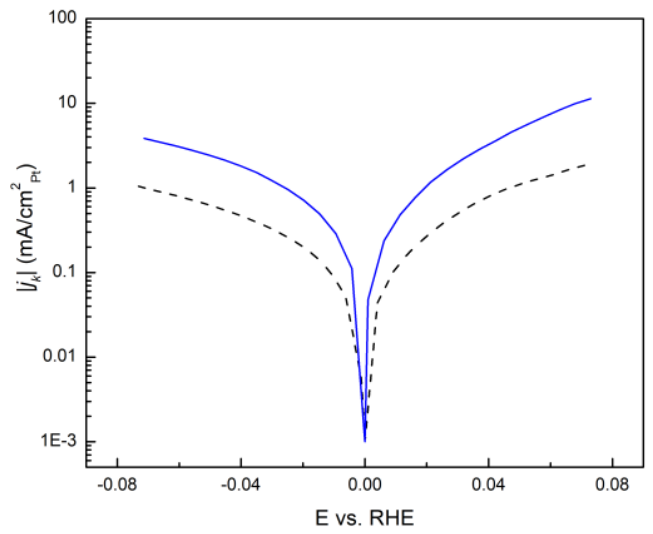

Figure S6: (a) CVs; (b) HER/HOR polarization curves (anodic sweep, scan rate: $20 \mathrm{mV} / \mathrm{s}$ ); (c) Tafel plot of HER/HOR polarization curve for $40 \mathrm{wt} \%$ commercial Pt/C (Pt loading: $15 \mu \mathrm{g} / \mathrm{cm}^{2}$ ) with caffeine (solid blue) and without caffeine (dashed black) 
a)

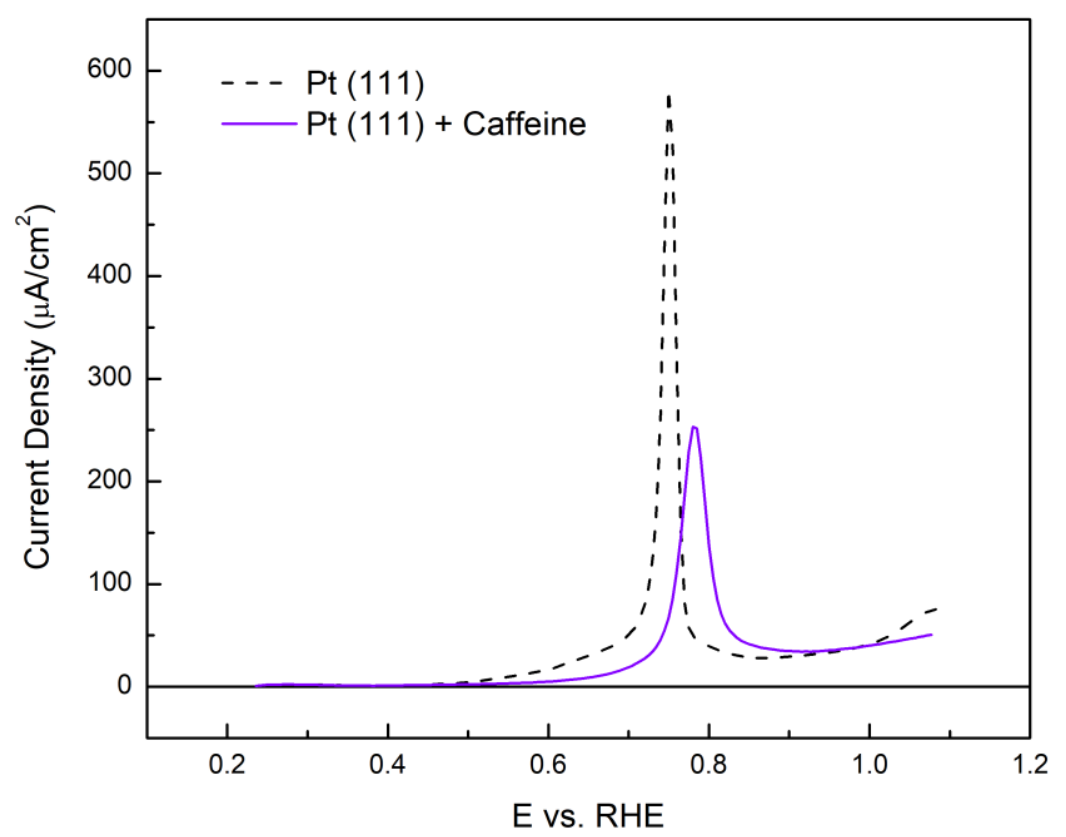

b)

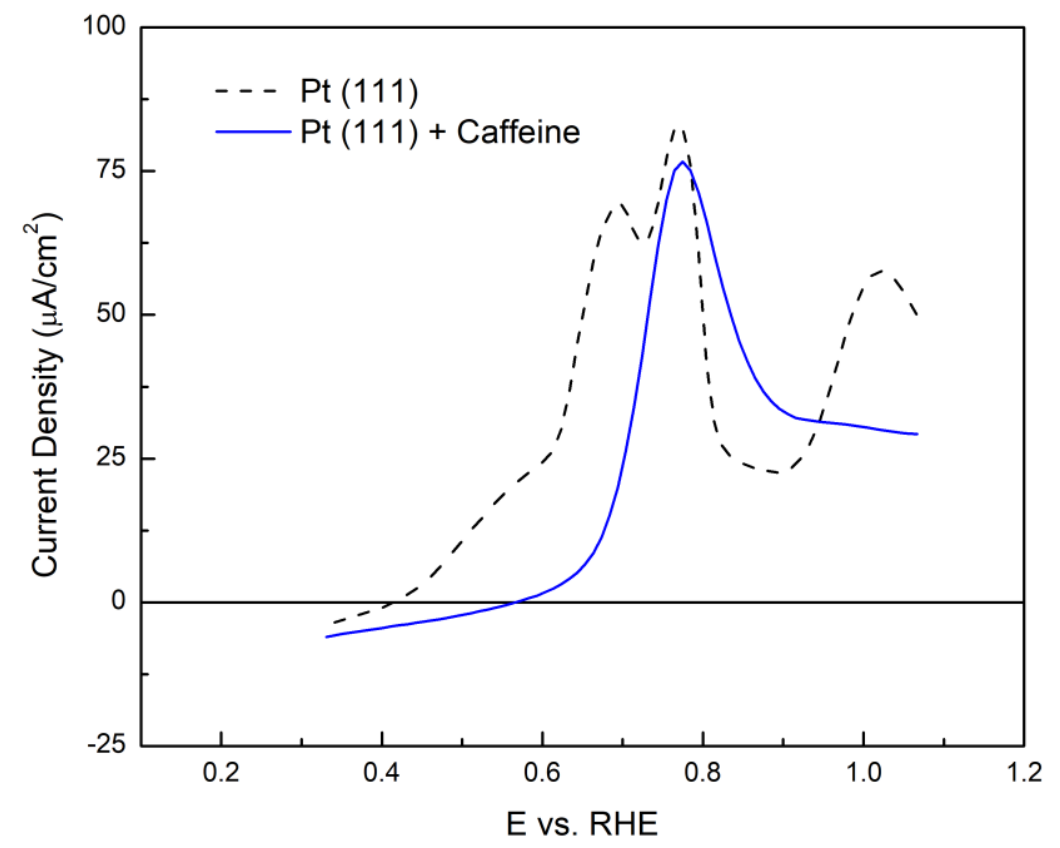

Figure S7: CO stripping curve of $\mathrm{Pt}$ (111) in Ar purged (a) $0.1 \mathrm{M} \mathrm{HClO}_{4}$ and (b) $0.1 \mathrm{M} \mathrm{KOH}$ (no caffeine in electrolyte) at a scan rate of $50 \mathrm{mV} / \mathrm{s}$. 
a)

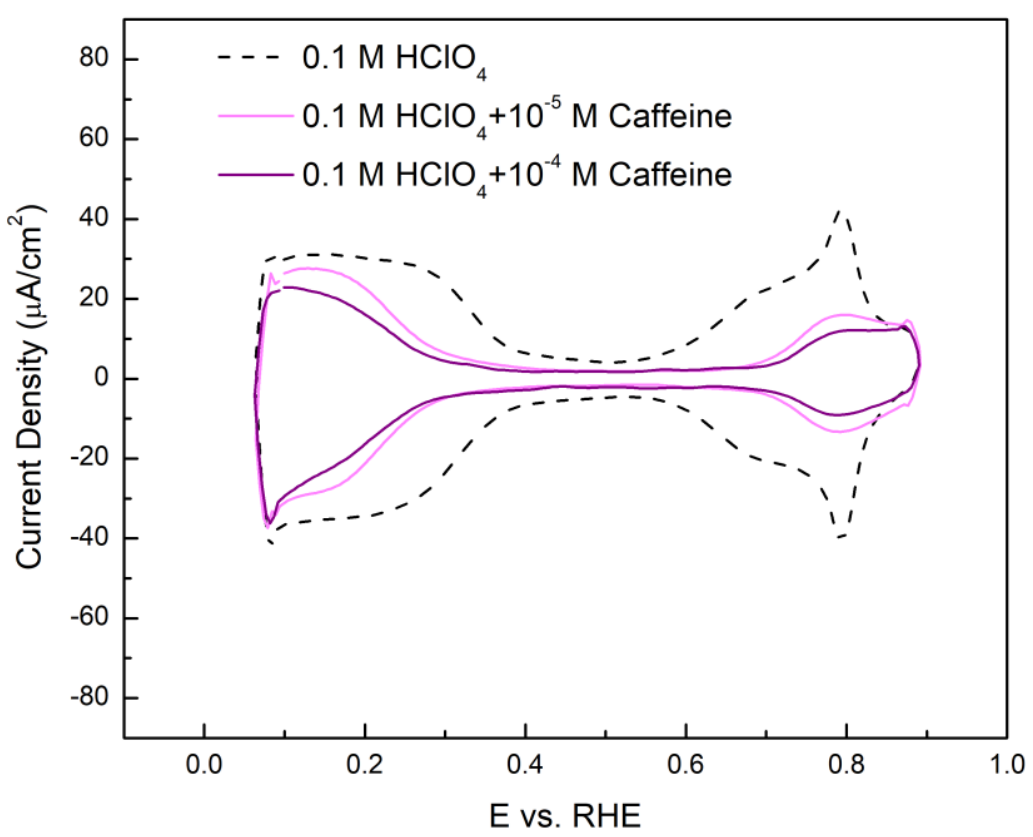

b)

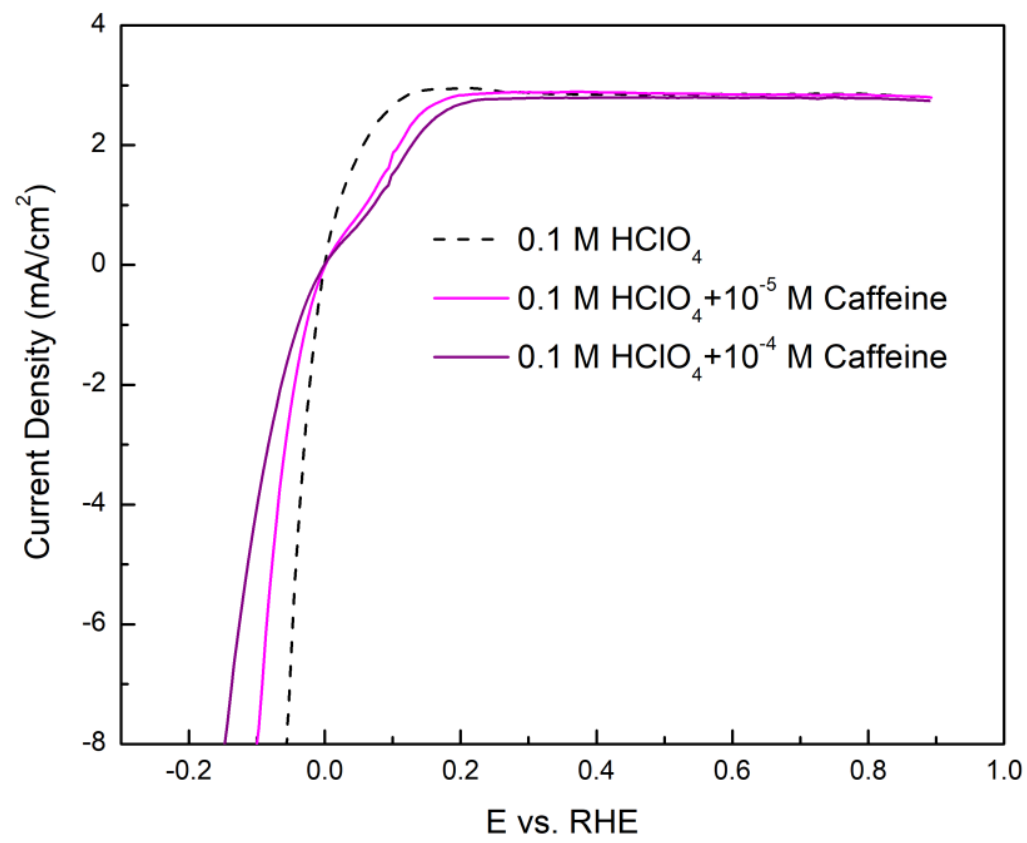

Figure S8: a) $\mathrm{CVs}$ and b) $\mathrm{HER} / \mathrm{HOR}$ polarization curves of $\mathrm{Pt}(111)$ in $0.1 \mathrm{M} \mathrm{HClO}_{4}$ with: no caffeine, $10^{-5} \mathrm{M}$ caffeine and $10^{-4} \mathrm{M}$ caffeine at a scan rate of $50 \mathrm{mV} / \mathrm{s}$. 


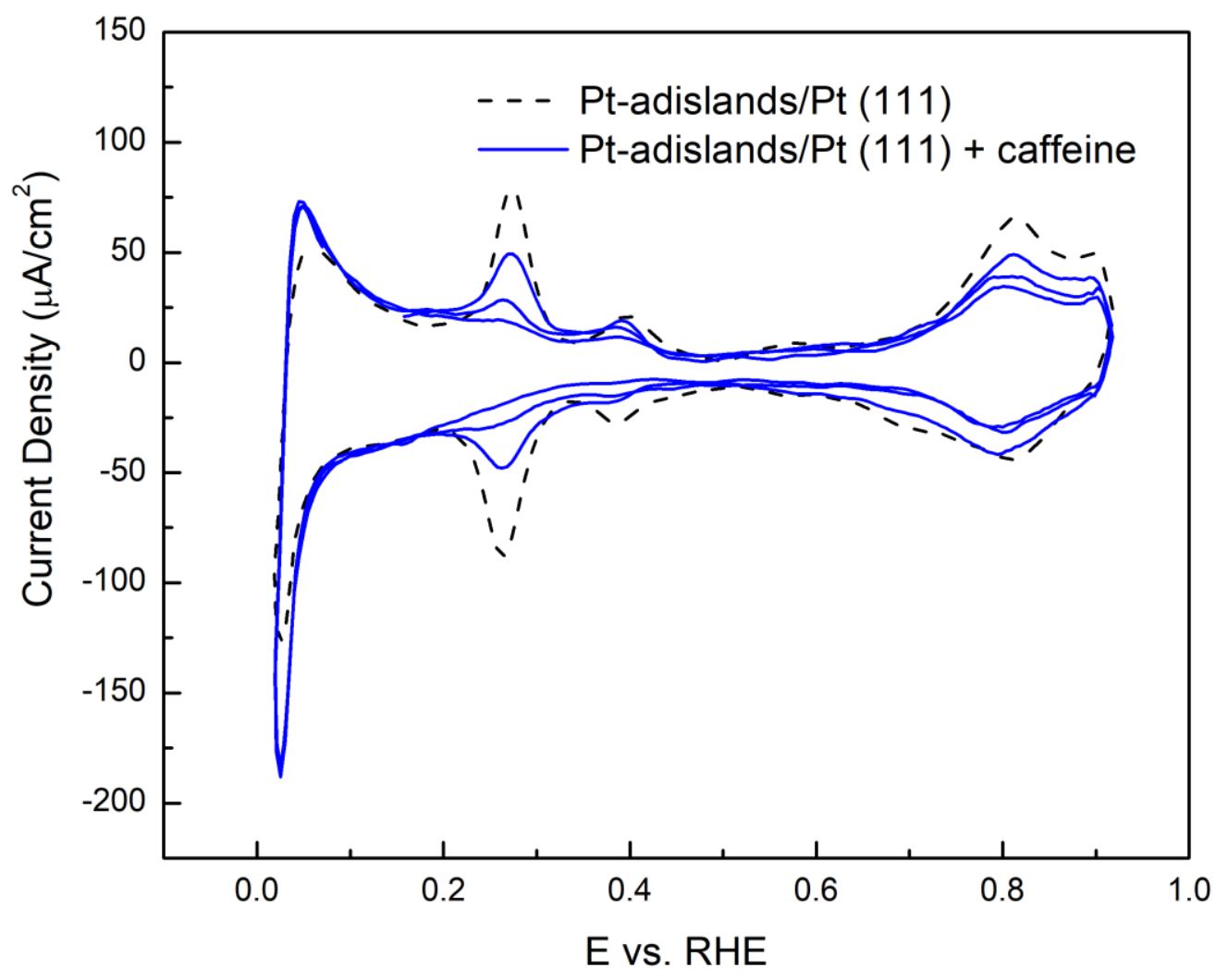

Figure S9: CV of Pt (111) + Pt adislands (high coverage) in Ar purged $0.1 \mathrm{M} \mathrm{KOH}$ at $50 \mathrm{mV} / \mathrm{s}$ with no caffeine and $10^{-5} \mathrm{M}$ caffeine. $\mathrm{CV}$ shows the slow suppression of $\mathrm{CV}$ features with each subsequent cycle. 


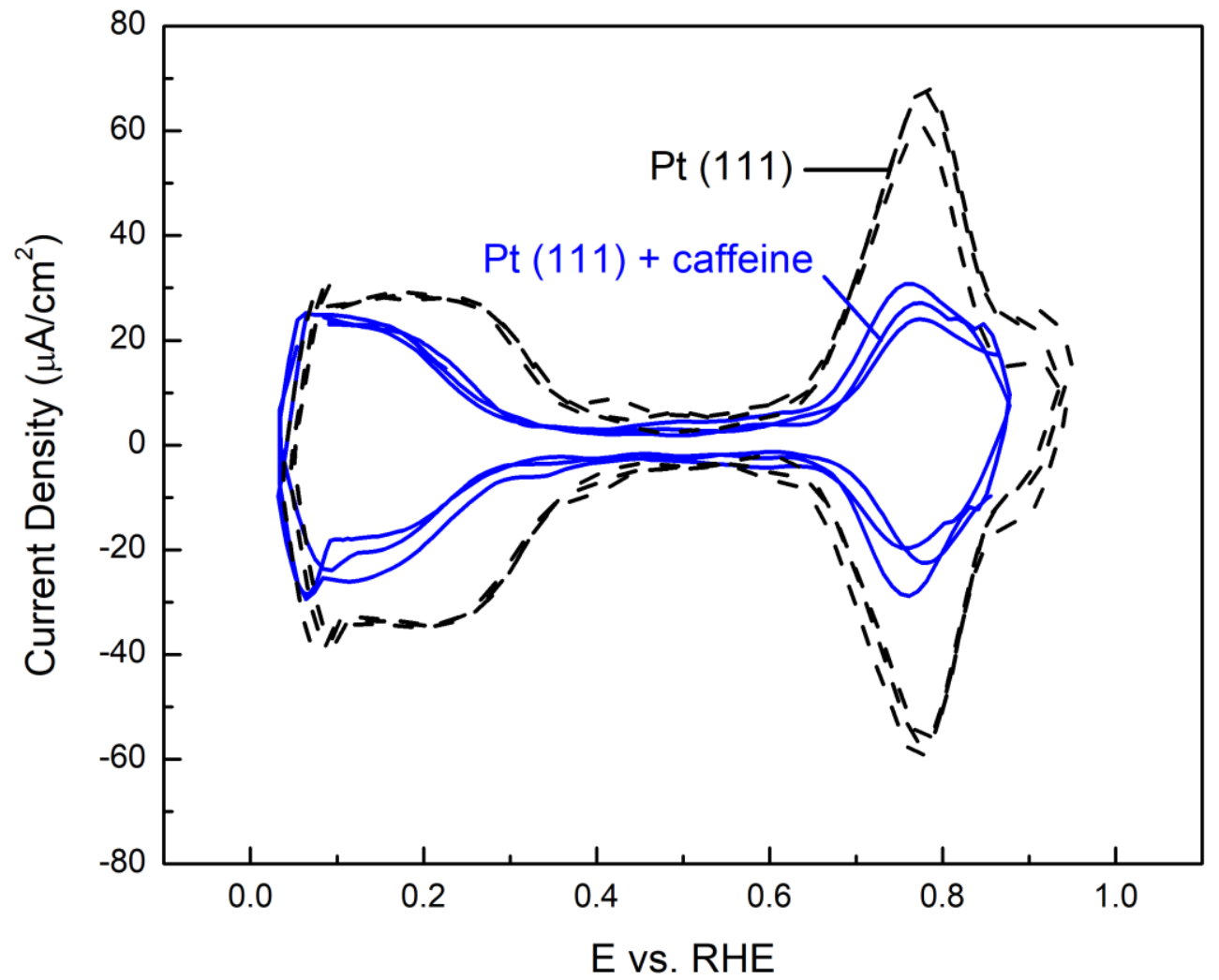

Figure S10: Reproducibility of cyclic voltammograms of Pt (111) in $0.1 \mathrm{M} \mathrm{KOH}$ 


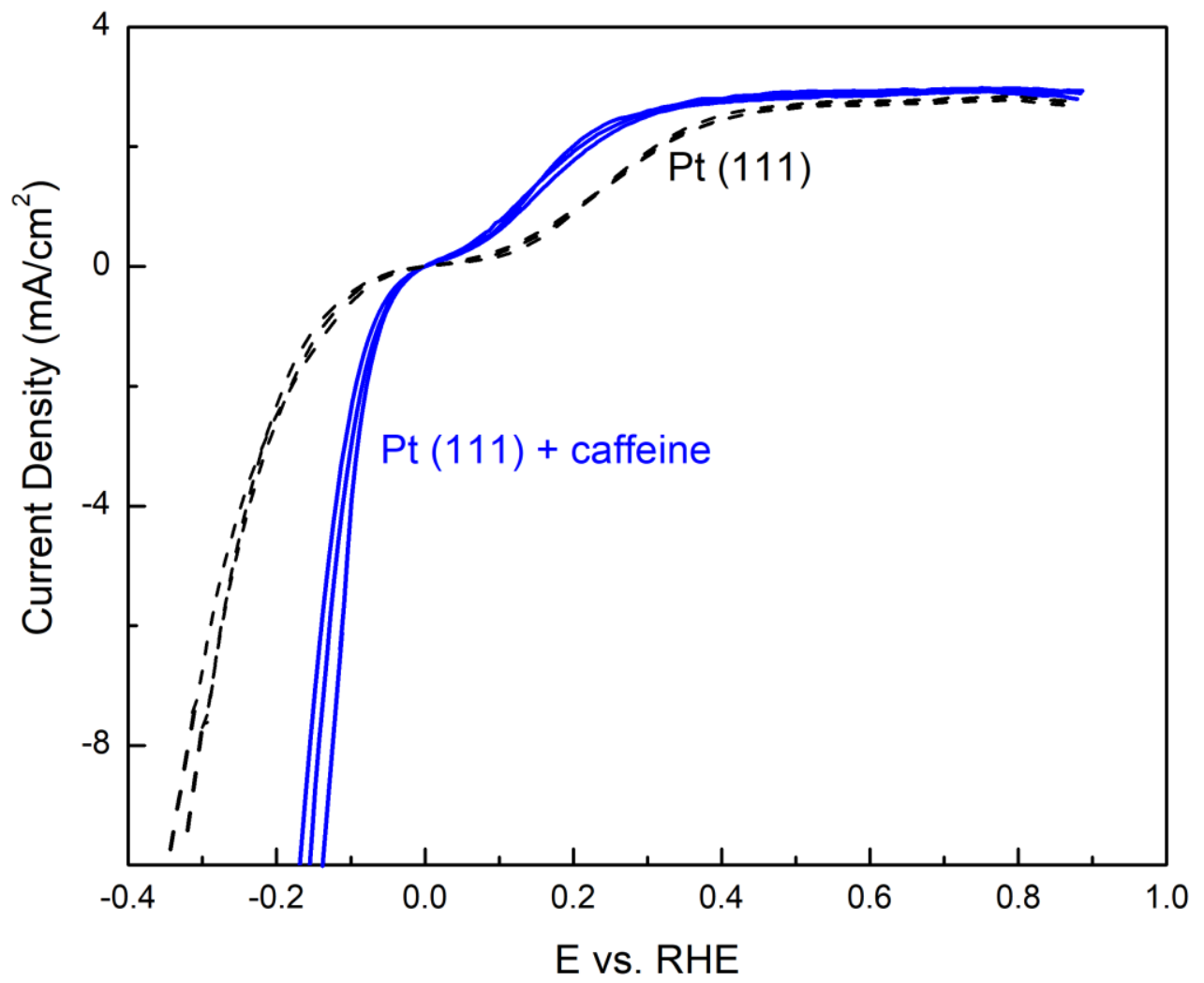

Figure S11: Reproducibility of HER-HOR polarization curves of Pt (111) in $0.1 \mathrm{M} \mathrm{KOH}$ 


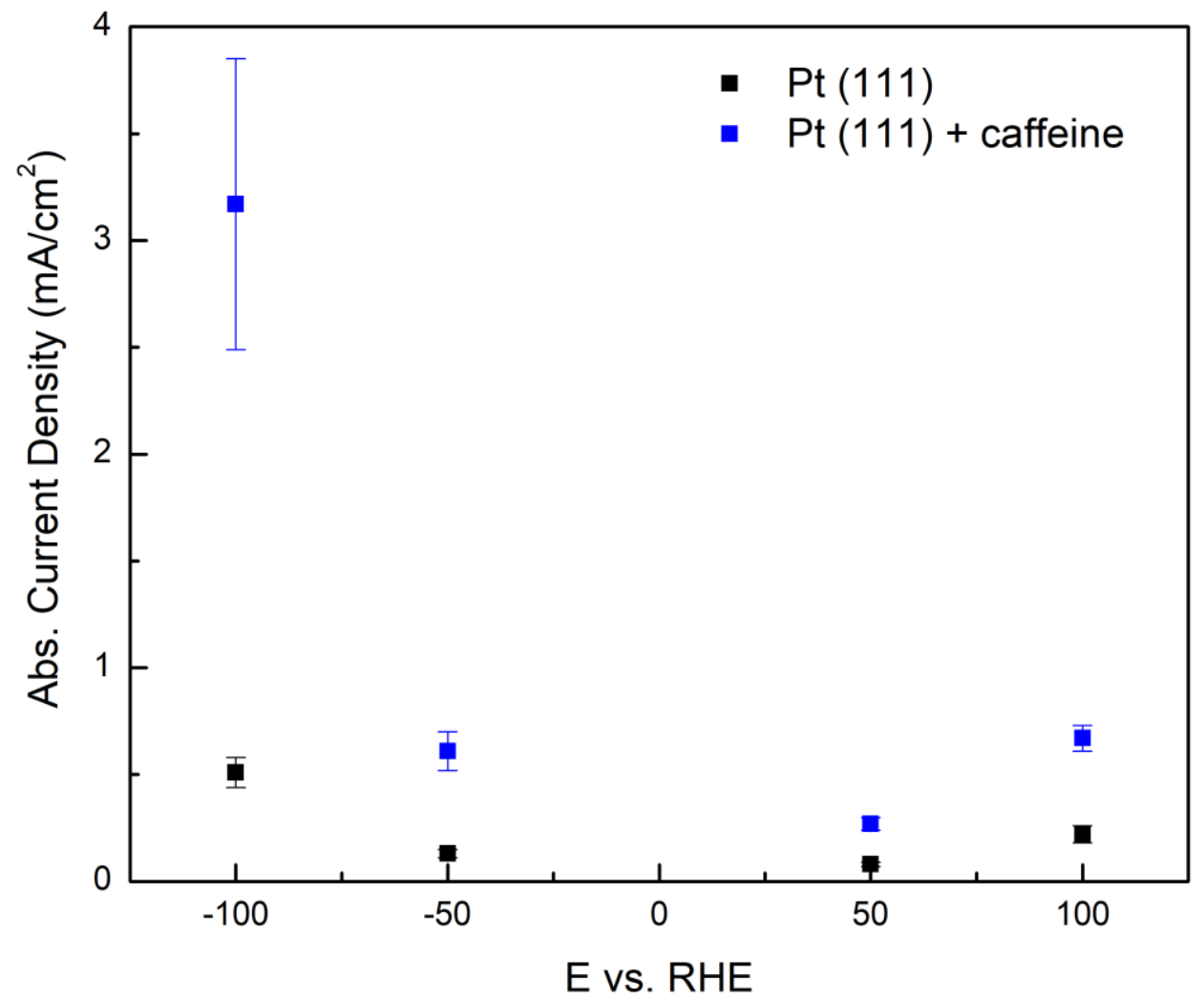

Figure S12: Absolute current densities for Pt (111) and Pt (111) + caffeine at various potentials in $0.1 \mathrm{M} \mathrm{KOH}$ with error bars. 
a)

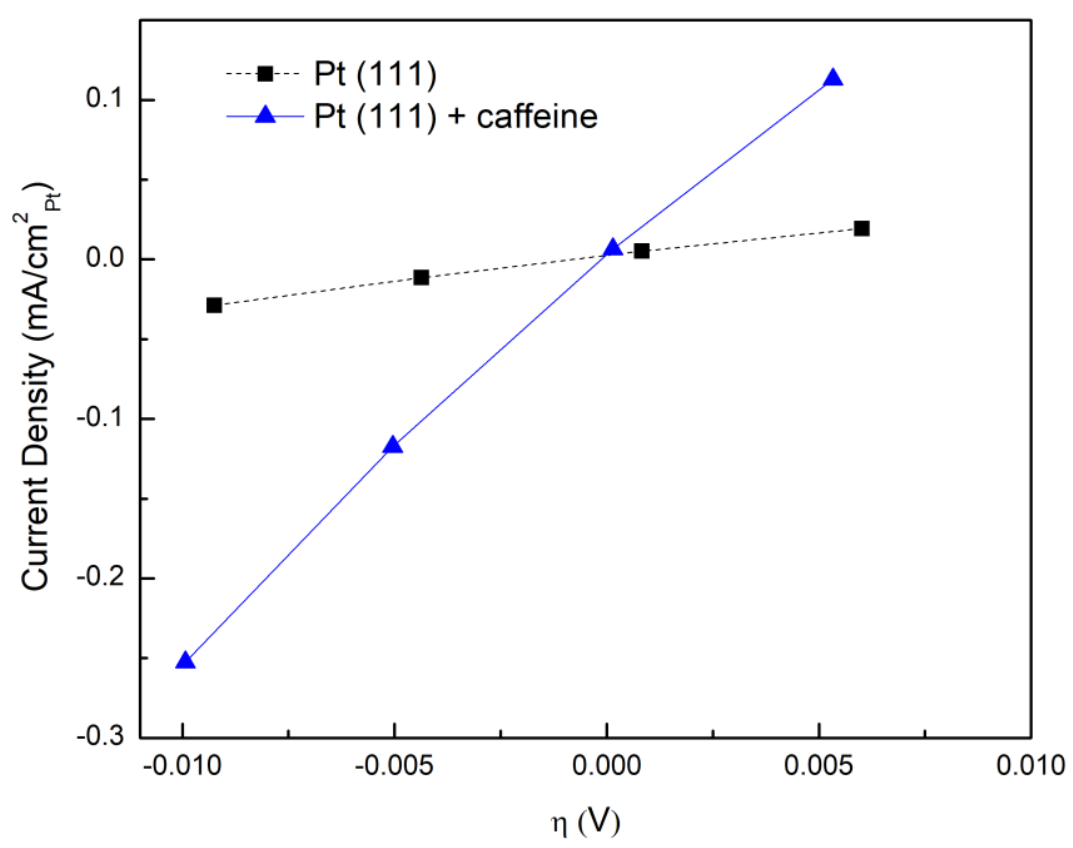

b)

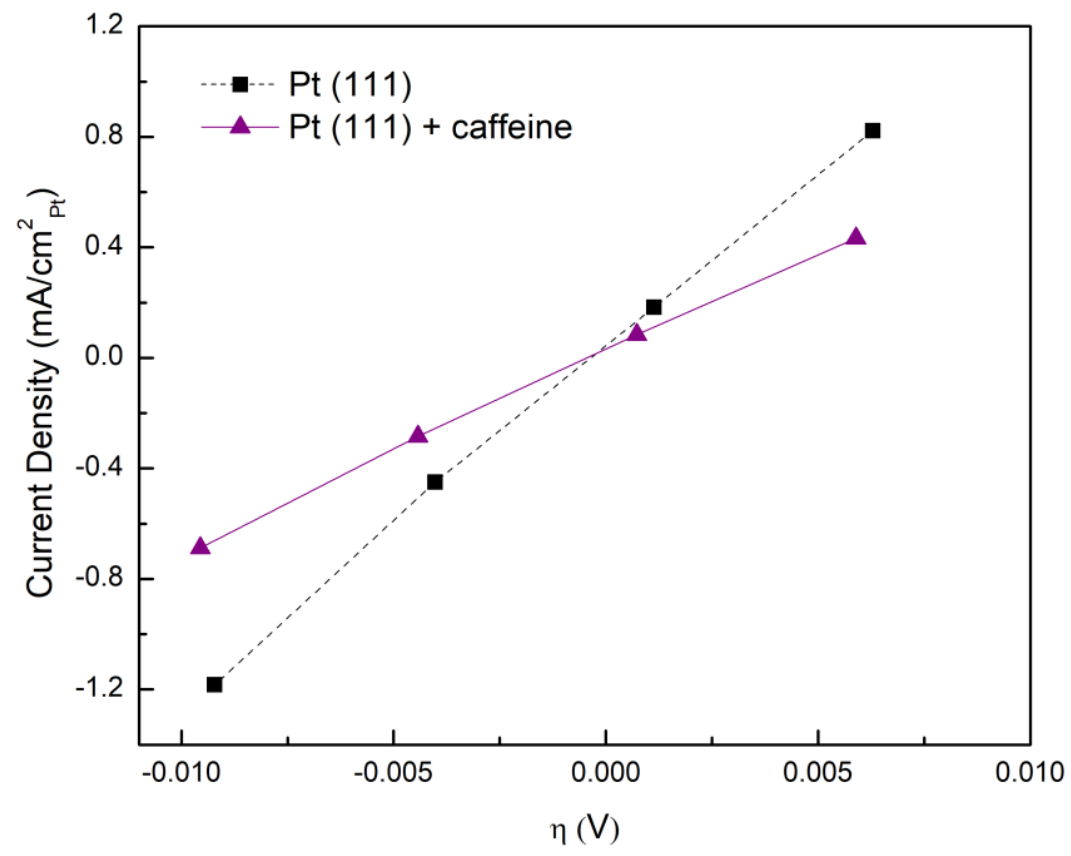

Figure S13: Low overpotential kinetic current density (normalized by Pt ECSA determined by $\mathrm{H}_{U P D}$ ) in $\mathrm{H}_{2}$ saturated (a) $0.1 \mathrm{M} \mathrm{KOH}$ and (b) $0.1 \mathrm{M} \mathrm{HClO}_{4}$. Exchange current density is equal to the slope of the lines multiplied by RT/F, where F is Faraday's constant, $\mathrm{R}$ is the ideal gas constant, and $\mathrm{T}$ is temperature. 
a)

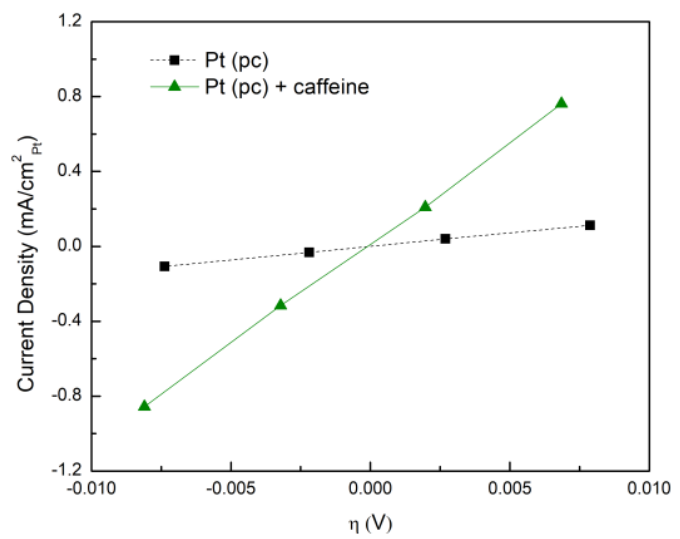

b)

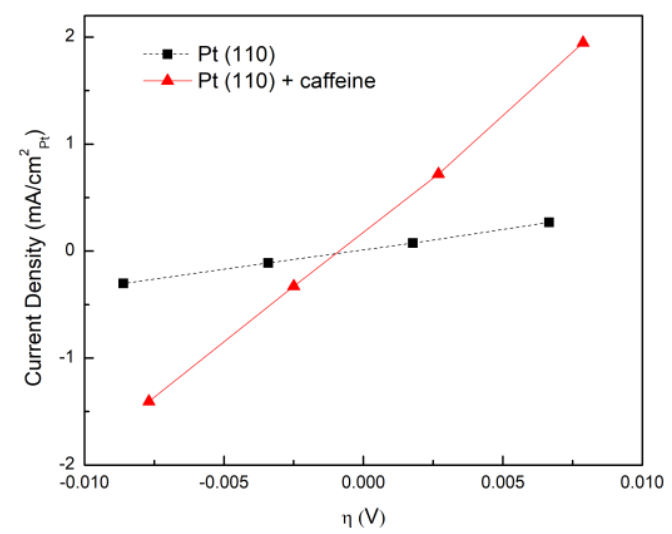

c)

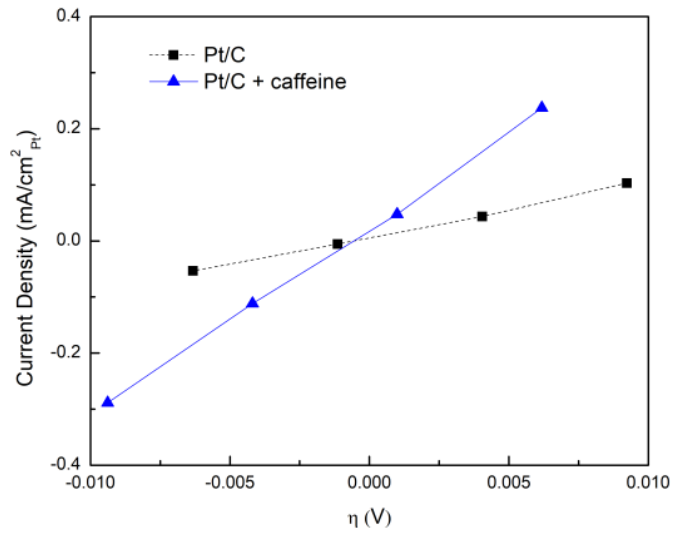

Figure S14: Low overpotential kinetic current density (normalized by Pt ECSA) in $\mathrm{H}_{2}$ saturated 0.1 M KOH for (a) Pt (pc) ; (b) Pt (110) and (c) Pt/C. Exchange current density is equal to the slope of the lines multiplied by RT/F, where F is Faraday's constant, $\mathrm{R}$ is the ideal gas constant, and $\mathrm{T}$ is temperature. 